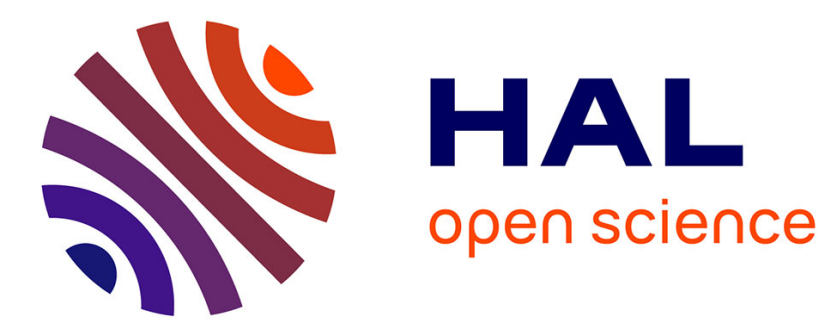

\title{
Constitutive model for granular materials considering grain breakage in finite deformations
}

Luis Berenguer Todo Bom, Arézou Modaressi

\section{To cite this version:}

Luis Berenguer Todo Bom, Arézou Modaressi. Constitutive model for granular materials considering grain breakage in finite deformations. European Journal of Environmental and Civil Engineering, 2016, 20, pp.971-1003. 10.1080/19648189.2014.960101 . hal-02458667

\section{HAL Id: hal-02458667 \\ https://hal-centralesupelec.archives-ouvertes.fr/hal-02458667}

Submitted on 4 Oct 2020

HAL is a multi-disciplinary open access archive for the deposit and dissemination of scientific research documents, whether they are published or not. The documents may come from teaching and research institutions in France or abroad, or from public or private research centers.
L'archive ouverte pluridisciplinaire HAL, est destinée au dépôt et à la diffusion de documents scientifiques de niveau recherche, publiés ou non, émanant des établissements d'enseignement et de recherche français ou étrangers, des laboratoires publics ou privés. 


\title{
Constitutive model for granular materials considering grain breakage in finite deformations
}

\author{
L. Berenguer-Todo-Bom ${ }^{\mathrm{a}, *}$, A. Modaressi-Farahmand-Razavi ${ }^{\mathrm{a}}$ \\ ${ }^{a}$ Laboratoire MSS-Mat CNRS UMR 8579,Ecole Centrale Paris, Grande Voie des Vignes, \\ 92290 Châtenay-Malabry, France
}

\begin{abstract}
Soil is subjected to shear stress and/or displacements in numerous geotechnical apllications. This lead to large number of numerical models being developed to represent its behaviour under various stress paths.

This paper aims to present a sound mechanical formulation for finite strains and to introduce a rational constitutive model to match realistically the behaviour of soil where, for a high range of deformations, strains localize and the phenomenon of grain breakage is usually observed in granular soil. The reference model is the ECP's constitutive model (also known as 'Hujeux's model') which is an elastoplastic multimechanism model. An overview is made of laboratory results and constitutive relations that consider finite deformation, and the grain breakage phenomenon that is usually associated with it in granular materials. The performance of the proposed constitutive model is demonstrated simulating constant volume ring shear tests carried out on Ottawa (OT) and Illinois River (IR) sands up to very high shear strains and comparison of the obtained results with laboratory testing data.
\end{abstract}

Keywords: Finite deformations, Elastoplasticity, Grain breakage, Soil-structure interaction

\footnotetext{
*Corresponding author

Email addresses: luis-andre.todo-bom@ecp.fr (L. Berenguer-Todo-Bom ), arezou.modaressi@ecp.fr (A. Modaressi-Farahmand-Razavi)
} 


\title{
Constitutive model for granular materials considering grain breakage in finite deformations
}

\begin{abstract}
Soil is subjected to shear stress and/or displacements in numerous geotechnical apllications. This lead to large number of numerical models being developed to represent its behaviour under various stress paths.

This paper aims to present a sound mechanical formulation for finite strains and to introduce a rational constitutive model to match realistically the behaviour of soil where, for a high range of deformations, strains localize and the phenomenon of grain breakage is usually observed in granular soil. The reference model is the ECP's constitutive model (also known as 'Hujeux's model') which is an elastoplastic multimechanism model. An overview is made of laboratory results and constitutive relations that consider finite deformation, and the grain breakage phenomenon that is usually associated with it in granular materials. The performance of the proposed constitutive model is demonstrated simulating constant volume ring shear tests carried out on Ottawa (OT) and Illinois River (IR) sands up to very high shear strains and comparison of the obtained results with laboratory testing data.

Keywords: Finite deformations, Elastoplasticity, Grain breakage, Soil-structure interaction
\end{abstract}

\section{Introduction}

Numerous physical and numerical modeling simulations have been performed in recent decades to explore the phenomena governing the behaviour of soils under high shear strains.

The simulation of geotechnical problems involving large shearing which takes place during pushed-in pile installations or landslides, among other applications, require some issues to be addressed. Finite deformations take place requiring an adjustment in the mechanical formulation of the constitutive model at the interface level to considering that the small deformations 
(rotations and strain) hypothesis is no longer valid. Moreover, the constitutive model must take into account the physical behaviour of the soil when subjected to high order of magnitude displacements. This article attempts to address these issues while modeling the behaviour of a soil subjected to very large shear displacements in a ring shear test device.

This article is divided into four parts: The first part is focused on the choice and adjustments of the mechanical formulation in order to cope with finite deformations based on an extensive bibliographic research. The prescribed formulation is detailed in this section.

The second part presents some remarks on laboratory test results from the pile-soil interface during installation and, finally, ring shear and triaxial tests where the behaviour of granular soil subjected to large shear displacements is studied in detail and the ruling physical phenomena are identified and quantified.

The third part discusses the modeling issues. First, the conditions at which strain localization may occur are briefly recalled and then the additional mechanism introduced in an incremental elastoplastic model (Aubry et al. (1982) Hujeux (1982)) to account for the behaviour of granular soil under large shear displacements namely the soil particles "crushability" is presented.

The final part consists of an application of the proposed formulation and constitutive model in the form of simulation results of shear tests with comparison to existing laboratory results. Different stress paths to which soil in the vicinity of piles is subjected are simulated and the role of grain breakage on the soil response is discussed through finite element computations.

\section{Finite deformation problematics}

Infinitesimal theories can be adopted to model the behaviour of inelastic solids as long as the strains and rotations remain sufficiently small $\mathrm{Wu}$ (2005). However, the deformations of solids under loading or imposed displacements can also be large in cases such as ductile fracture, impact and damage analysis, metal forming processes, soil mechanics, etc. This evidence led to development of constitutive laws to model material behaviour beyond the infinitesimal deformation range, both in elastic and plastic domains.

Since most theories of material behaviour (relationship between deformation and stress) are written considering the infinitesimal deformation hypoth- 
esis most of the effort concerning the finite deformation range has been the extension of these theories. This extension is not, however, straightforward and it has lead to different opinions, approaches and heated debates in the scientific community. The extension of these theories encounters issues with the stress and strain measures, decomposition of strain in elastic and plastic parts, the stress rate, observer independent yield function and rotation of material texture, among others Xiao et al. (2006).

The expression of finite deformations or large deformations is usually associated with problems where differences between the undeformed and deformed states, important geometrical changes, cannot be neglected when considering the constitutive law of the material under analysis. Finite deformation analysis must take into consideration the complexity due to strong non-linearity in geometry. Such complexity lies not only in the definition of various strain measures but also in their conjugate stress measures (as well as their rates). Therefore, a key issue is then which configuration (reference state or current state) should be used to form the equations that will govern the material's behaviour de Souza et al. (2008).

\subsection{Mechanical formulation}

The physical pertinence and simplicity of the specific form of a constitutive function (yield function, flow rule, etc.) would suggest that the most appropriate constitutive variables should be those which can, in a natural and direct manner, characterize and represent the physical essence and feature of the deformation behaviour under consideration. In finite deformation, the natural deformation rate $\mathbf{D}$ with flow-like characteristics leads to a direct extension of the separation of infinitesimal strain. The rate of deformation D tensor can then be separated in two parts because of its linear relationship with the velocity gradient:

$$
\mathbf{D}=\mathbf{D}^{e}+\mathbf{D}^{p}
$$

In the previous expression $\mathbf{D}^{e}$ and $\mathbf{D}^{p}$ are called elastic and plastic stretching respectively and represent the instantaneous elastic and plastic deformation increments over an infinitesimal time interval, each being referred to the current configuration. The pair $\mathbf{D}^{e}$ and $\mathbf{D}^{p}$ may be regarded to represent the recoverable and irrecoverable parts of the total work increment. The definitions of basic mechanical quantities are presented in the Appendix A of this paper. 
An Eulerian formulation has a direct physical pertinence, conceptual clarity and structural simplicity Xiao et al. (2006). These advantages may be amicable to efficient numerical treatment with finite element codes. However, the issue of how to select suitable rates for the formulation arises since the solution to the objectivity requirement is far from being trivial (Johnson and Bammann (1984) Liu and Hong (1999) Liangsen et al. (1999)). Multiple studies have been done specially dedicated to this purpose considering the five "classical" stress rates: Jaumann, Green-McInnis or Green-Naghdi, Cotler-Rivlin, Oldroyd's and Truesdell stress rates. Also, troublesome nonuniqueness and multiplicity of the separation of $\mathbf{D}$ would persist in the presence of infinitely many possible objective rates implying too many different characterizations of the elastic stretching $\mathbf{D}^{e}$ for the recoverable energy part (elastic).

A consistent Eulerian formulation by Xiao et al. (1997) has been proposed based upon two consistency criteria, yielding stationarity and elastic integrability, which avoid the serious problems of inconsistency accompanied by arbitrariness, uncertainty and limitations of the previous stress rate attempts (Xiao et al. (2000) Bruhns et al. (2001) Meyers et al. (2005) Naghdabadi et al. (2005)).

The first consistency criteria is in the form of Prager's criterion: "The simultaneous vanishing of the stress rate, back stress and hardening parameters should render the yield function stationary". It should be noted that, despite the issues with the Jaumann stress rate, the applicability of this criterion to Eulerian rate formulations of finite plasticity is universal.

The second consistency criteria consists of the complete integrability of elastic behaviour. This implies the establishment of a self-consistent elastic rate formulation where $\mathbf{D}^{e}$ can characterize recoverable elastic behaviour. It has been shown by Simo and Pister (1984) that the Eulerian rate equation of hypoelastic type arises the integrability issue which relies on the definition of the stress rate. In other words, the criterion of elastic integrability, introduced by Bruhns et al. (1999), namely "for every process of elastic deformations with $\mathbf{D}=\mathbf{D}^{e}$, the rate equation should be exactly integrable to deliver a dissipationless elastic relation and hence really characterize recoverable elastic behaviour", is not verified.

Finally, the uniqueness property of the logarithmic rate in the above solutions is considered. Recently it has been demonstrated that there is one and only one choice for the stress rate such that the elastic equation satisfies the integrability criterion. Obviously, from the definition of objective 
corotational stress rates, if the definition of the stress rate is unique so is the spin tensor by which it is defined. These are respectively the logarithmic stress rate $\left(\boldsymbol{\sigma}^{l o g}\right)$ and logarithmic spin tensor $\left(\boldsymbol{\Omega}^{\log }\right)$.

$$
\boldsymbol{\sigma}^{\log }=\frac{\partial}{\partial t}(\boldsymbol{\sigma})-\boldsymbol{\Omega}^{\log } \cdot \boldsymbol{\sigma}+\boldsymbol{\sigma} \cdot \boldsymbol{\Omega}^{\log }
$$

where the defining equation for $\mathbf{D}$ is such that

$$
\mathbf{D}=\frac{\partial}{\partial t}(\ln \mathbf{V})-\Omega^{\log } \cdot \ln \mathbf{V}+(\ln \mathbf{V}) \cdot \mathbf{\Omega}^{\log }=(\ln \mathbf{V})^{\log }
$$

By considering the logarithmic stress rate, it can be rewritten as

$$
(\ln \mathbf{V})^{\log }=\mathbf{D}
$$

The separation of $\mathbf{D}$ is taken as an independent starting-point. Considering that, as said before, $\mathbf{D}$ is solely related to the ever-changing current configuration, $\mathbf{D}^{e}$ and $\mathbf{D}^{p}$ need not be related to any "elastic" or "plastic" deformation quantities relative to either a fixed referential or a changing intermediate configuration. To sum up, consistent constitutive formulations should be established where $\mathbf{D}^{e}$ is indeed elastic (recoverable) while $\mathbf{D}^{p}$ is definitely plastic-like (dissipative) Xiao et al. (2006). The elastic rate equation of grade zero will be written as

$$
\boldsymbol{\sigma}^{\log }=2 \mu \mathbf{D}^{e}+\lambda \operatorname{tr}\left(\mathbf{D}^{e}\right) \mathbf{I}
$$

Moreover, it is found that the solution for the hypoelastic equation considering the logarithmic stress rate for a no stress initial condition of $\boldsymbol{\sigma}=\mathbf{0}$ the previous equation can be written as

$$
\boldsymbol{\sigma}=2 \mu \ln \mathbf{V}+\lambda \operatorname{tr}(\ln \mathbf{V}) \mathbf{I}
$$

In this equation, as it has been demonstrated by Xiao et al. (1997), the Cauchy stress and the logarithmic strain can form a conjugate pair of stress and strain. Now returning to the definition of the logarithmic stress tensor, 
moreover, the definition of the logarithmic spin tensor, an explicit basis-free expression of the "log-spin" $\boldsymbol{\Omega}^{\log }$ in terms of $\mathbf{D}, \mathbf{W}$ and $\mathbf{B}$ is as follows:

$$
\mathbf{\Omega}^{\log }=\mathbf{W}+\mathbf{N}^{\log }
$$

where $\mathbf{N}^{\log }= \begin{cases}0 & \text { if } b_{1}=b_{2}=b_{3} \\ v[\mathbf{B} \cdot \mathbf{D}] & \text { if } b_{1} \neq b_{2}=b_{3} \\ v_{1}[\mathbf{B} \cdot \mathbf{D}]+v_{2}\left[\mathbf{B}^{2} \cdot \mathbf{D}\right]+v_{3}\left[\mathbf{B}^{2} \cdot \mathbf{D} \cdot \mathbf{B}\right] & \text { if } b_{1} \neq b_{2} \neq b_{3}\end{cases}$

in which $\mathbf{B}=\mathbf{V}^{2}$ is the left Cauchy-Green tensor and $b_{i}=\lambda_{i}^{2}, \quad \mathbf{i}=1,2,3$ are its eigenvalues. The bracket is defined here by

$$
\left[\mathbf{B}^{r} \cdot \mathbf{D} \cdot \mathbf{B}^{s}\right]=\mathbf{B}^{r} \cdot \mathbf{D} \cdot \mathbf{B}^{s}-\mathbf{B}^{s} \cdot \mathbf{D} \cdot \mathbf{B}^{r}
$$

The other parameters in the equation are here defined as

$$
\begin{gathered}
v=\frac{1}{b_{1}-b_{2}}\left(\frac{1+b_{1} / b_{2}}{1-b_{1} / b_{2}}+\frac{2}{\ln b_{1} / b_{2}}\right) \\
v_{k}=-\frac{1}{\Delta} \sum_{i=1}^{3}\left(-b_{i}\right)^{3-k}\left(\frac{1+\epsilon_{i}}{1-\epsilon_{i}}+\frac{2}{\ln \epsilon_{i}}\right), k=1,2,3 \\
\Delta=\left(b_{1}-b_{2}\right)\left(b_{2}-b_{3}\right)\left(b_{3}-b_{1}\right), \\
\epsilon_{1}=\frac{b_{2}}{b_{3}}, \quad \epsilon_{2}=\frac{b_{3}}{b_{1}}, \quad \epsilon_{3}=\frac{b_{1}}{b_{2}}
\end{gathered}
$$

It should be pointed out that the skewsymmetric tensor $\mathbf{N}^{\log }$ is a particular form of the general skewsymmetric tensor derived by Dafalias (1985) in the investigation of the plastic spin. Also, from the above one can notice that the explicit basis-free expressions presented enables us to determine the $\log$-spin $\boldsymbol{\Omega}^{\log }$ directly using the deformation gradient $\mathbf{F}$ given under any coordinate system. 
It can be shown that not only the simple shear response but all possible responses of the hypoelastic model based on the log-rate agree with those of the finite deformation isotropic elastic model by the grade zero elastic rate equation.

The approach considering the logarithmic stress rate never attempts to separate the total elastoplastic deformation $\mathbf{F}$ and therefore satisfies to the basic idea of the earlier Eulerian rate formulation employing physical pertinent quantities. The resultant constitutive formulation might not only be physically pertinent but is also endowed with a simple structure.

Thus a consistent, physically pertinent formulation of finite elastoplasticity is attained considering the inherent inseparability of the total elastoplastic deformation as a physical entity since a proper definition of elastic behaviour is unavoidably linked with an elastic or plastic deformation-like variable, is attained.

The Eulerian formulation for finite strains with logarithmic rate will be used henceforth in the mechanical formulation and constitutive model of this study.

The interested reader can find a more complete coverage of this topic in Truesdell (1955), Green and Naghdi (1971), Simo and Pister (1984), Dafalias (1985), Naghdi (1990), Xiao et al. (1997), Bruhns et al. (1999), Xiao et al. (2000), Fish and Shek (2000), Bruhns et al. (2001), Meyers et al. (2005), Naghdabadi et al. (2005), Wu (2005), Xiao et al. (2006) and Chakrabarty (2006).

\section{Laboratory test results}

Push-in pile installation and landslides are two typical cases among others where the soil undergoes large deformations and evidence of particle crushing in the localized shear zone has been observed. Moreover, phenomena such as sliding-surface liquefaction and/or mobilized shear resistance reduction which could be explained by the contractive volume change induced by grain crushing phenomenon Okada et al. (2005).

The pile installation example is pursued here for the study of soil subjected to large shear strains and its effects of structures. Laboratory-scale investigations into pile behaviour remain popular because of the high cost of field testing and the possibility of achieving specific soil characteristics in a laboratory environment Lehane and White (2005). On one hand, $1 \mathrm{~g}$ or centrifuge tests are performed on small scale model piles to explore deformation 
patterns and stress distributions in soil and pile capacity equations and their sensitivity to various installation procedures with respect to soil and pile parameters. On the other hand, shear tests on soil specimens are carried out to study the soil behaviour under various soil and interface conditions. In what follows we will give a summary of such laboratory tests focusing on those related to the physical phenomena which occur during installation of push-in piles where the soil-pile interface undergoes large shear displacements.

- Physical modelling of pile installation

White and Bolton (2002) and White and Bolton (2004) performed calibration chamber testing combined with a new technique of displacement measurement which used image analysis to study the penetration of a jacked pile. The Dog's Bay carbonate sand which is known to suffer particle breakage was used. The behaviour of the soil adjacent to the pile is thoroughly analyzed because the study is focused on the known"friction fatigue" phenomena where the radial stress and thus the shaft friction experience a sharp decrease behind the pile tip. It is found that the "friction fatigue", as a function of the radial stress acting on the pile-soil interface, appears to be somewhat a combination of two factors: a contraction at the interface level due to continued shearing White and Bolton (2004) and an unloading of the radial stresses of the zone next to the soil-pile interface layer.

The contraction at the soil-pile interface level is considered to be due to particle rearrangement and repacking as a consequence of the pile rough surface (this rearrangement is considered to be more important with increasing number of cycles D'Aguiar et al. (2009)) and to fine broken particles that move away from the interface.

For sands susceptible to particle breakage this effect can be quite relevant leading to significant granulometric changes. White and Bolton (2004) present a series of plane strain calibration chamber tests to quantify both the pile base and shaft whilst installation of the pile (pushed-in) is performed. It is found that the volumetric variation of the soil near the soil-pile interface during the pile installation process is of major importance for the mechanical behaviour of the interface. Some of this variation is an irrecoverable volume reduction from grain crushing due to continued shearing White and Bolton (2004). Yang et al. (2010), who performed calibration chamber and ring shear testing, note that 'it is clear that pile installation in pressurized sand involves particle breakage and shear band formation'. The shear bands 
are constituted of broken soil particles forming beneath the pile tip. It is found that considerable grain breakage takes place at the interface level during monotonic pile installation. Yang et al. (2010) consider that monotonic ring shear tests generate an interface layer that is comparable to the one obtained for the soil-pile interface layer during calibration chamber testing as well as broadly similar patterns of interface roughness, in spite of leading to thinner shear zones and lower proportions of fractured sand.

- Ring shear and triaxial tests

Ring shear testing (RS) is a practical and valid tool to explore soil behaviour under very large shear displacements including shear and normal stresses application, initiation of bifurcation and shear band development among others.

Okada et al. (2005) performed ring shear and triaxial tests, under drained and undrained conditions, on fine silica sand and Osaka-group coarse sandy soils. It is found that critical state conditions (deformation at constant volume, constant normal effective stress, constant shear stress and constant velocity) cannot be attained with standard triaxial testing. The results are similar to those obtained by Sadrekarimi and Olson (2011a). Lower shear resistances are obtained in RS tests than in triaxial tests. Two phase transformation points are found for dilative specimens and it is interpreted from the undrained tests that the decrease in shear resistance is related to an increase in pore pressure (contraction) as a result of considerable grain crushing in the specimens. In order of magnitude, the variation of the height of the specimen in drained tests is more substantial than the pore pressure variation in the undrained tests. This is due, as interpreted by the authors, to the fact that the pore pressure can never surpass the total normal stress whereas, in the drained tests, variation in specimen height can continue as long as grain crushing does not cease. This behaviour can be observed in Figure 1 in the ring shear tests for silica sand but the same behaviour, qualitatively, is also found in medium-dense and dense Osaka-group coarse sandy soils. Similar behaviour was found by Sassa et al. (2004) in undrained dynamic loading using the ring shear apparatus.

Sadrekarimi and Olson (2010a) tested in the ring shear apparatus (height of the soil specimen in the apparatus is $2.6 \mathrm{~cm}$ ) three different sands: Ottawa sand (OT), Illinois River sand (IR) and Mississippi River sand (MR). Substantial particle damage was found in the shear band but no particle damage 


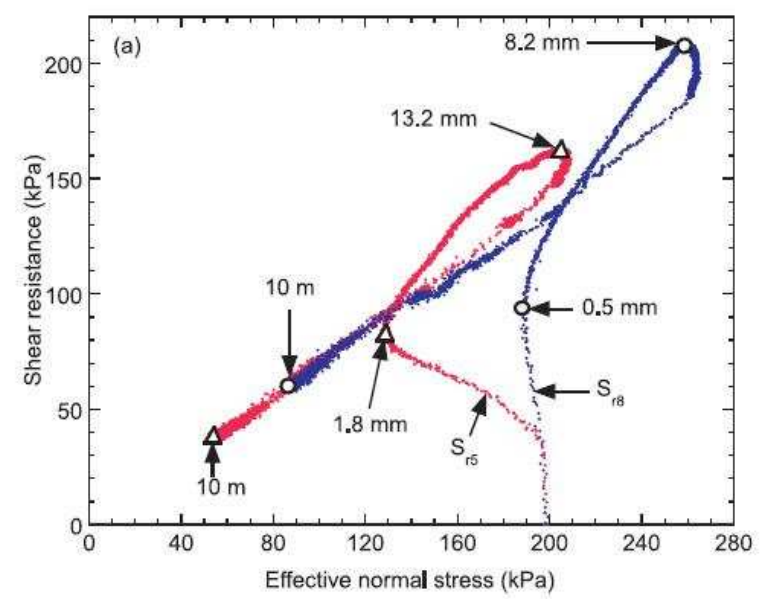

Figure 1: Effective-stress paths of medium-dense and dense silica sand $\left(S_{r 5}: e_{0}=0.98\right.$ ; $\left.S_{r 8}: e_{0}=0.86\right)$ in undrained shear tests where the displacements are indicated Okada et al. (2005)

above the shear band occurred. Competing shearing mechanisms were found to be at play for OT and IR sands: dilation and particle damage (contractive behaviour). It usually started with dilative behaviour leading to shear resistance increase until the occurrence of the second phase transformation and ending with net contraction due to particle damage and decrease in shear resistance until reaching a critical state (a zero volume variation state). It should be noted that according to the grain size distribution curves, obtained before and after shearing, high levels of particle crushing were found (Figure 2) as a result of these tests.

Sadrekarimi and Olson (2010b) focused on particle damage during ring test shearing, for Ottawa sand (OT), Illinois River sand (IR) and Mississippi River sand (MR), where it is found that stress concentration at particle asperities and the torque applied to individual sand particles during shearing are the main mechanisms for particle damage. More particle damage is found to occur in drained RS tests than in constant volume tests. The particle damage effects on stress-strain response found in drained conditions are that it causes contraction in the shear band even for initially dilative specimens. Similar to previous tests Sadrekarimi and Olson (2010a), as particle damage increases it overcomes dilation and produces net contraction 


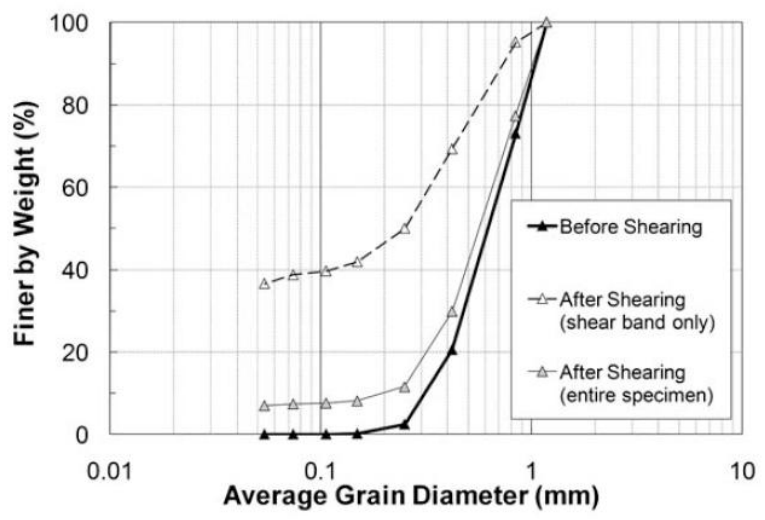

Figure 2: Grain-size distributions of IR sand before and after RS testing Sadrekarimi and Olson (2010a)

(2nd phase transformation) which continues until normal stresses are small enough to cease particle damage and the critical state is reached.

Figure 3 and Figure 4 presented by Sadrekarimi and Olson (2010b) show the evolution of the shear band and the stress paths for RS tests in OT sand. The different steps identified by letters, (a) to (d), in the plots are explained by Sadrekarimi and Olson (2010b) where (a) is the first transformation point, (b) is the initiation of bifurcation, (c) is the second transformation point (in constant volume tests) and (d) is the end of the tests.

Sadrekarimi and Olson (2011b) considered the effect of large shear displacements, where grain crushing occurs, on the normal compression line (NCL) and the critical state line (CSL) for Ottawa sand (OT), Illinois River sand (IR) and Mississippi River sand (MR) in RS and triaxial tests. They find that for IR and OT sands they start and remain mostly parallel even at large shear displacements. However, both CSL and NCL lines become much steeper with shearing. For MR sand, only the CSL becomes steeper and the NCL does not change significantly.

Sadrekarimi and Olson (2011a) studied the effect of large shear displacements in RS and triaxial tests on the critical friction angle for the same sand as in Sadrekarimi and Olson (2011b). The friction angle is shown to increase with particle damage since it produces a wider particle size distribution and more angular particles. It is shown to be independent of stress path, initial fabric, initial void ratio and consolidation stress but depending primarily on 

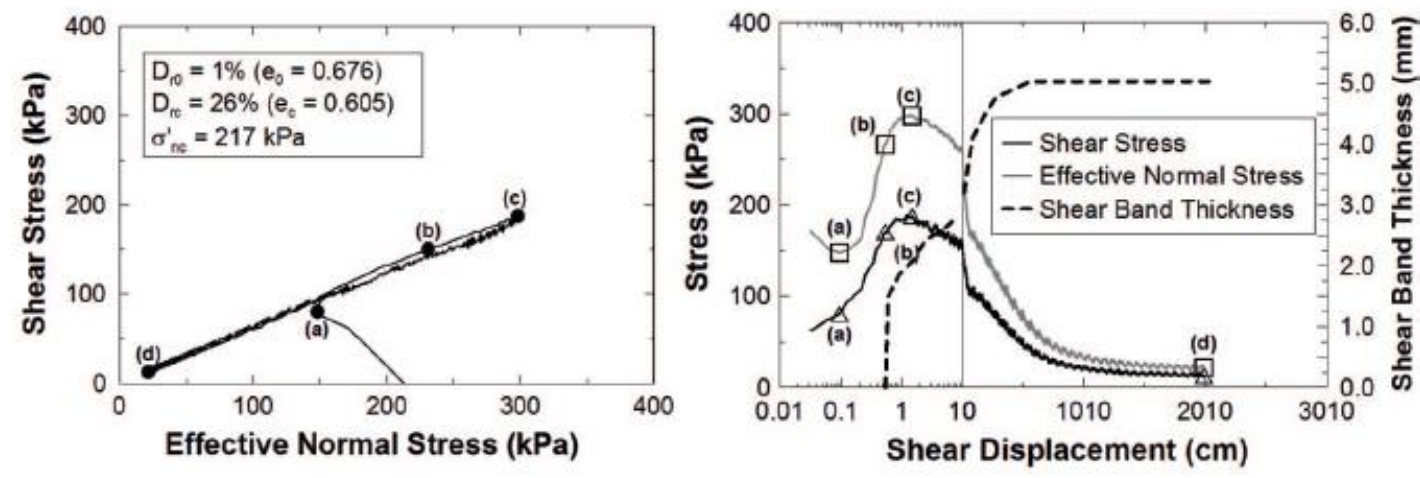

Figure 3: Shear band evolution and corresponding stress paths and stress-displacements plots in constant volume RS tests on OT sand Sadrekarimi and Olson (2010b)

particle mineralogy, shape and the intermediate principal stress. The triaxial tests are found not to reach the second transformation point.

From the works summarized here it can be seen that, despite the fact that both shear and normal stresses are relatively low during the tests performed, high levels of particle crushing are found which brings into question the notion that crushing only occurs at elevated levels of stress in the soil. It may be assumed that high levels of shear strain will produce high stresses at the asperities of particles which can result in considerable particle damage. 

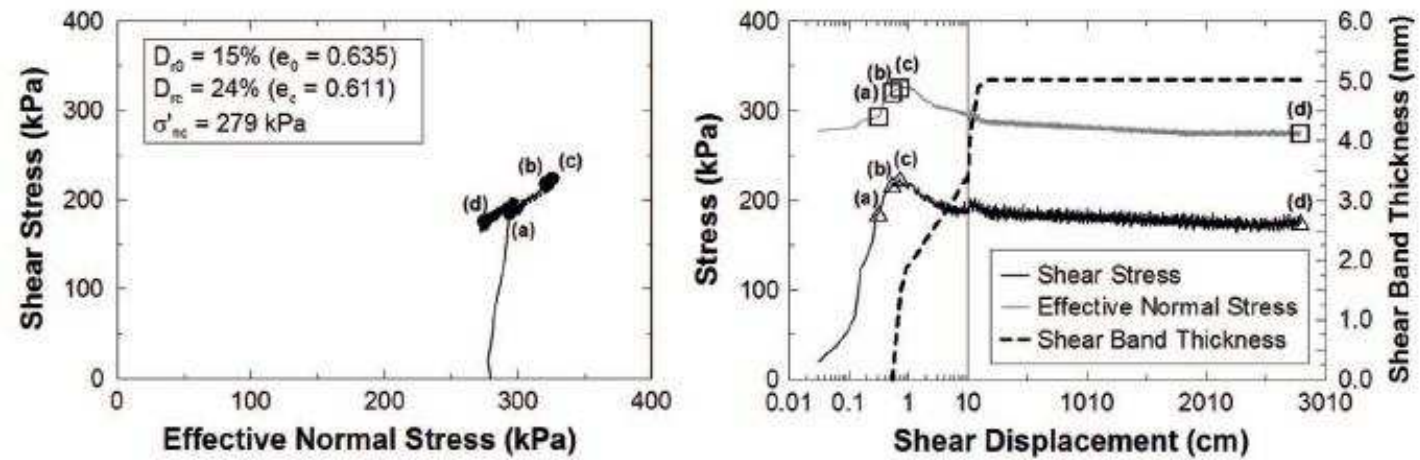

Figure 4: Shear band evolution and corresponding stress paths and stress-displacements plots in drained stress paths RS tests on OT sand Sadrekarimi and Olson (2010b)

\section{Soil constitutive model}

Numerous authors have proposed constitutive models to tackle the behaviour of soil specimens subjected to grain crushing and large shear displacements, namely at the interface level (Desai and Ma (1992) Mortara et al. (2002) Gennaro and Frank (2002)), in order to simulate geotechnical structures. A brief summary of some of the models is presented henceforth. Cecconi et al. (2002) formulated a model developed for a pyroclastic soil coarse-grained soft rock. The central assumption is that the frictional properties of the material change with the development of plastic strains and propose three variables to model that change. The properties that are considered to change include the friction angle, the elastic domain and NCL slope, and finally a parameter that controls the yield locus shape. The change of the friction angle implies a change in the classical stress-dilatancy formulation. The model focuses on grain crushing effects despite borrowing heavily from the effects of debonding (loss of structure) in terms of mathematical formulation. Russell and Khalili (2004) propose a model where the critical state line (CSL) in the volumetric-stress space steepens when grain crushing occurs and then flattens at some point. The critical state line takes the form of 3 linear segments dependent on the stress level interval. The phases are: particle rearrangement in sliding and rotation, particle crushing (substantially more contraction) and finally particle crushing is no longer the main factor (contraction reduces considerably leading to an almost flat CSL). The model 
considers the Roscoe dilatancy rule (the critical state line separates between contractive and dilative states of the stress path Roscoe et al. (1958)) and friction angle is considered to be a constant which is validated by triaxial testing. Salim and Indraratna (2004) proposed a model which is based on an extra internal variable dependent on the back-calculation of triaxial test results. This internal variable is the breakage index which requires laboratory testing to be defined and hence adds 5 additional parameters that are required for the breakage mechanism. The plastic flow rule, based on Roscoe dilatancy rule, incorporates the breakage variable and a Mohr-Coulomb yield locus is considered. Hu et al. (2011) propose a model with two yield surfaces: shear sliding (Roscoe dilatancy rule) and isotropic compression (associated flow rule). A breakage function is proposed connecting the evolution of the CSL to the energy consumed relating implicitly the position of the CSL to gradation. The position of the CSL is defined by Biarez's correlation between peak friction angle and intrinsic friction angle using the present void ratio and the critical void ratio Biarez and Hicher (1994). Void ratio depends on breakage index therefore the breakage index is correlated with the CSL while considering the gradation of the specimen.

From the models presented here none attempts to model the second transformation phase seen in some of the laboratory tests. A great deal of attention is given to the determination of the evolution of gradation by some of the models but the furthest that these models consider is to limit or annul dilation but not in reversing the volumetric behaviour. The proposed model in this article attempts to address that behaviour of the soil subjected to large shear strain.

\subsection{ECP constitutive model}

The ECP's constitutive model, commonly known as Hujeux model, is an elastoplastic multimechanism model (Aubry et al. (1982) Hujeux (1982) Modaressi (2003) Daouadji et al. (2001) and Sica et al. (2008)) characterized by different yield surfaces, allowing for an anisotropic response. It also incorporates critical state soil mechanics and considers a Coulomb failure line. The model is defined with a very small elastic domain were the behaviour is nonlinear elastic. Isotropic hardening with plastic strains represents the effect of compressive effective pressure in soil (barotropy) and the progressive mobilization of the friction. The latter is also a result of isotropic hardening due to increasing plastic deviatoric strains. Cyclic behaviour is defined by kinematic hardening of the yield surfaces and the internal variables with 
discontinuous evolution laws. The flow rule is associated for the isotropic mechanism and deviatoric plastic strains while a Roscoe type dilatancy rule Roscoe et al. (1958) governs the volumetric plastic deformations generated by the deviatoric mechanisms. The isotropic nonlinear elastic behaviour is represented in the model by an evolution of the elastic variables with the mean compressive effective stress. The bulk and shear modulus, K and G, are determined as

$$
\begin{aligned}
& K\left(p^{\prime}\right)=K_{\text {ref }}\left(\frac{p^{\prime}}{p_{\text {ref }}^{\prime}}\right)^{n_{e}} \\
& G\left(p^{\prime}\right)=G_{\text {ref }}\left(\frac{p^{\prime}}{p_{\text {ref }}^{\prime}}\right)^{n_{e}}
\end{aligned}
$$

where $K_{r e f}$ and $G_{r e f}$ are the moduli measured at the reference pressure $p_{r e f}^{\prime}$ and $n_{e}$ is the degree of non-linearity $\left(n_{e}=0\right.$ corresponds to linear elasticity).

The model has one isotropic and three deviatoric mechanisms defined in orthogonal planes. For each deviatoric plastic mechanism "k" associated with a plastic plane strain, a projection matrix $\mathbf{O}_{k}$ is defined in the base plane $\left(\mathbf{e}_{i}, \mathbf{e}_{j}\right)$ with $\mathbf{e}_{k}$ as the normal vector, such that:

$$
\boldsymbol{\sigma}_{k}=\mathbf{O}_{k} \boldsymbol{\sigma} \mathbf{O}_{k}
$$

where $\mathbf{O}_{k}$ is

$\mathbf{O}_{k}=\mathbf{e}_{(1+\bmod (k, 3))} \otimes \mathbf{e}_{(1+\bmod (k+1,2))}+\mathbf{e}_{(1+\bmod (k+1,3))} \otimes \mathbf{e}_{(1+\bmod (k, 2))} \quad, \quad k \in[1,2,3](16)$

and $\bmod (k, j)$ is the remainder of the division of $k$ by $j$. Thus,

$$
\begin{aligned}
& \mathbf{O}_{1}=\mathbf{e}_{2} \otimes \mathbf{e}_{3}+\mathbf{e}_{3} \otimes \mathbf{e}_{2} \\
& \mathbf{O}_{2}=\mathbf{e}_{1} \otimes \mathbf{e}_{3}+\mathbf{e}_{3} \otimes \mathbf{e}_{1} \\
& \mathbf{O}_{3}=\mathbf{e}_{2} \otimes \mathbf{e}_{1}+\mathbf{e}_{1} \otimes \mathbf{e}_{2}
\end{aligned}
$$


This projection which results in the following form for the stress tensor associated to the "k" plane, verifies the plastic plane strain hypothesis in this plane

$$
\boldsymbol{\sigma}_{k}=\sigma_{i i} \mathbf{e}_{i} \otimes \mathbf{e}_{i}+\sigma_{j j} \mathbf{e}_{j} \otimes \mathbf{e}_{j}+\sigma_{i j}\left(\mathbf{e}_{i} \otimes \mathbf{e}_{j}+\mathbf{e}_{j} \otimes \mathbf{e}_{i}\right)
$$

The variables considered per mechanism can therefore be defined

$$
\begin{array}{r}
p_{k}^{\prime}=\frac{\operatorname{tr}\left(\boldsymbol{\sigma}_{k}^{\prime}\right)}{2} \\
\mathbf{s}_{k}=\boldsymbol{\sigma}_{k}^{\prime}-p_{k}^{\prime} \mathbf{I}_{k} \\
q_{k}=\left\|\boldsymbol{s}_{\boldsymbol{k}}\right\| \\
D_{v k}=\operatorname{tr}\left(\mathbf{D}_{k}\right) \\
\mathbf{D}_{D k}=\mathbf{D}_{k}-D_{v k} \mathbf{I}_{k}
\end{array}
$$

where

$$
\mathbf{I}_{k}=\mathbf{e}_{i} \otimes \mathbf{e}_{i}+\mathbf{e}_{j} \otimes \mathbf{e}_{j}
$$

$\mathrm{D}$ is the rate of deformation tensor (symmetric) that can be decomposed in $\mathbf{D}^{e}$ and $\mathbf{D}^{p}$ which are called elastic and plastic stretching respectively as presented in Section 2. Also, $\mathbf{D}^{p}=\sum_{k=1,4} \mathbf{D}_{k}^{p}$ where only active mechanisms contribute.

The yield criterion for a given deviatoric plane " $k$ " is defined by

$$
f_{k}\left(\boldsymbol{\sigma}, p_{c}, r_{k}\right)=q_{k}-p_{k} \cdot \sin \phi_{p p} \cdot r_{k} \cdot\left(1-b \cdot \ln \left(\frac{p_{k}}{p_{c}}\right)\right) \leq 0
$$

where 


$$
\dot{p}_{c}=p_{c} \beta \operatorname{tr}\left(\mathbf{D}^{p}\right) \quad, \quad \dot{r_{k}}=\dot{\Lambda} \frac{\left(1-r_{k}\right)^{2}}{a}
$$

The expressions presented here introduce material properties. The parameter " $\beta$ " is the plastic compressibility modulus which serves to represent the influence of the densification in the material behaviour and is taken into account in the state variable " $p_{c}$ " (pycnotropy). This parameter defines the variation of " $p_{c 0}$ " which corresponds to the critical mean effective stress at the initial void ratio. Parameter " $\phi_{p p}$ " is the friction angle of the material representing the critical state line (state where deformation occurs at constant volume) in the stress plane and " $b$ " is a parameter that defines the shape of the yield surface. A value of " $b=1$ " represents a Cam-Clay-type yield surface and " $b=0$ " a Mohr-Coulomb-type yield surface. The variable " $r_{k}$ " represents the deviatoric hardening variable. This variable starts at an initial value " $r_{k}^{e l}$ ", representing the size of the deviatoric elastic domain, and evolves until the value of unity at the perfect plasticity state. The parameter " $a$ " has a great influence on the evolution of the deviatoric hardening, a lower value of " $a$ " leads to faster increase of the hardening parameter. This variable varies with the deviatoric deformations according to the relationship proposed by Hujeux (1982)

$$
a=a_{1}+\left(a_{2}-a_{1}\right) \alpha\left(r_{k}\right)
$$

where $\alpha\left(r_{k}\right)$ evolves depending on the interval where the value of $r_{k}$ is

$$
\alpha\left(r_{k}\right)=\left\{\begin{array}{lll}
0 & \text { if } r_{k}<r_{h y s} & \text { pseudo-elastic domain } \\
\left(\frac{r_{k}-r_{h y s}}{r_{m o b}-r_{h y s}}\right)^{m} & \text { if } r_{h y s}<r_{k}<r_{m o b} & \text { hysteretic domain } \\
1 & \text { if } r_{m o b}<r_{k}<1 & \text { mobilized domain }
\end{array}\right.
$$

Finally, $\dot{\Lambda}$ is the plastic multiplier.

The deviatoric mechanisms are subjected to a non-associated flow rule based on a Roscoe dilatancy rule Roscoe et al. (1958)

$$
\mathbf{D}_{k}^{p}=\dot{\Lambda} \cdot \frac{1}{2} \cdot\left[\frac{\boldsymbol{s}_{\boldsymbol{k}}}{q_{k}}+\left(\sin \psi-\frac{q_{k}}{p_{k}}\right) \mathbf{I}_{k}\right]
$$


where $\psi$ is the characteristic angle associated with a zero volume variation and divides the stress plane in contractive and dilative behaviour (first phase transformation / characteristic line). Data shows that usually $\phi=\psi$ and that relative density does not influence either of the two lines Lade and Ibsen (1997).

Figure 5 shows the graphical representation of the phase transformation and instability lines. The instability line is defined as the line in stress space where the plastic strain increment vector is perfectly vertical and indicates a point where sand may become unstable Hill (1958). For the revised ECP constitutive model the definition of these lines is crucial.

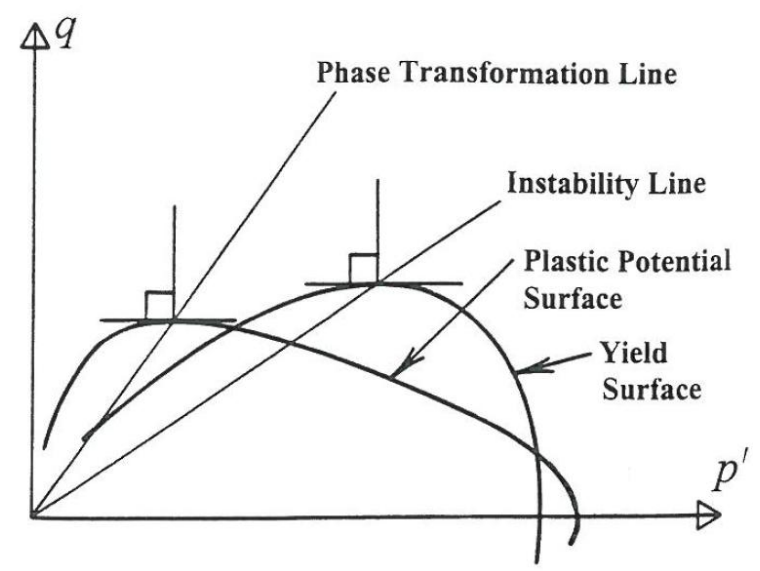

Figure 5: Comparison of phase transformation and instability lines Lade and Ibsen (1997)

In the ECP constitutive model the position of the instability line is dependent on a number of parameters. Figure 6 shows the influence of the initial normal stress while Figure 7 shows the influence of parameter " $b$ " on the position of the instability line for a certain initial normal stress in the model for an undrained shear loading path.

The ECP multimechanism model also includes an isotropic mechanism which is governed by the spheric part of the stresses and produces only volumetric variations. The yield criterion of the forth mechanism, the isotropic mechanism, is given by

$$
f_{4}=f_{\text {iso }}=\left|p^{\prime}\right|-d p_{c} r_{i s o}
$$




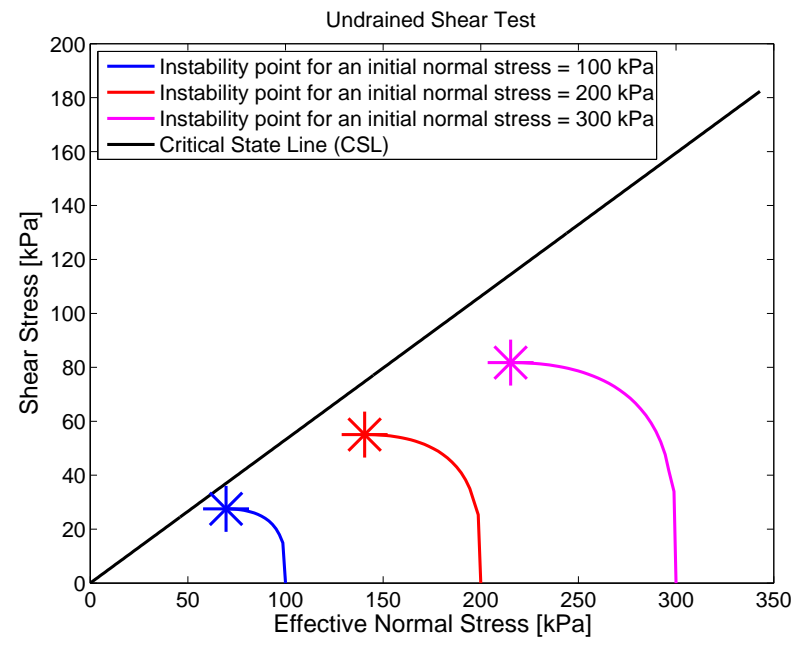

Figure 6: Influence of the initial normal stress on the position of the instability line

where

$$
\dot{r}_{i s o}=\dot{\Lambda} \frac{\left(1-r_{i s o}\right)^{2}}{c} \frac{p_{r e f}}{p_{c}}
$$

The parameter " $d$ " represents the distance between the normal consolidation line and the critical state line in the volumetric plane and the parameter "c", mirroring the parameter " $a "$ in the deviatoric hardening, controls the isotropic hardening. It can be seen that as all four mechanisms "share" the volumetric strain variable they are coupled.

\subsection{Revised ECP constitutive model}

In order to consider the behaviour of soil when subjected to significant shear strains the constitutive model has to take into account the main physical phenomena taking place under such conditions. As the laboratory testing results show, special features must be introduced into the constitutive models and numerous authors have proposed different constitutive models to tackle this issue of which some were already presented in Section 3.

In this section a revised version of the ECP constitutive model valid to represent the behaviour of soil under large strains where the second phase 


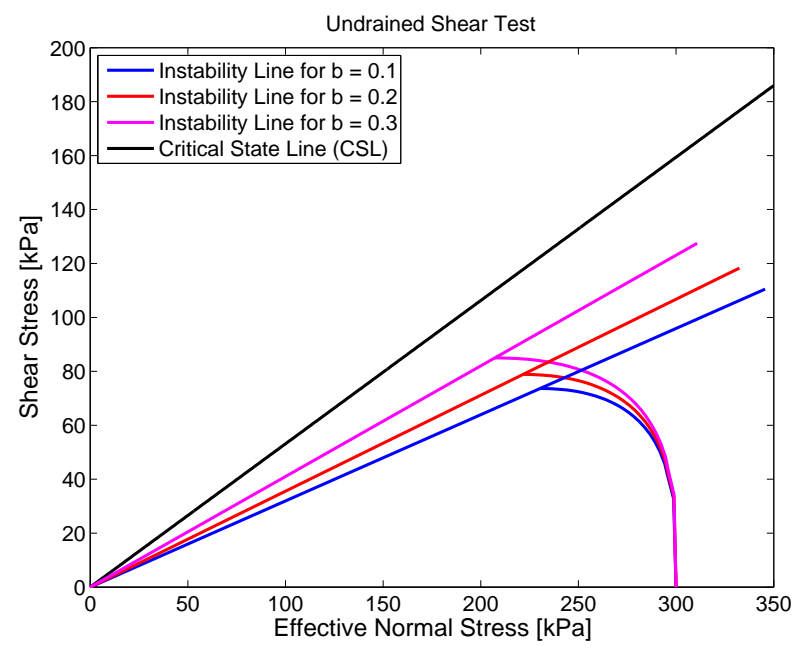

Figure 7: Influence of parameter $b$ on the position of the instability line

transformation occurs is presented. The need for modifications in the constitutive model will be better demonstrated with the model application at the end of the article. Some could readily be observed in the results from RS testing where the second phase transformation occurs.

From pile experimental results Yang et al. (2010) results it can be seen that the soil specimens underwent extreme shearing as well as high compression stresses in the vicinity of the moving pile which resulted in particle damage and influenced the volumetric behaviour and stiffness of the specimen White and Bolton (2004). The shearing processes are addressed considering the results from $\mathrm{RS}$ tests. The isotropic compression mechanisms are not addressed from isotropic compression tests. Instead, only ring shear tests volumetric measurements are considered due to a lack of laboratory results concerning sands for a trend to be identified. This is because most existing results consider coarser granular materials. By not being addressed from isotropic compression tests, it is meant that the behaviour of soil specimens under isotropic compression (such as the models from Hu et al. (2011) and Einav (2007) as well as laboratory studies such as Hagerty et al. (1993) and McDowell et al. (1996)) was not considered in the formulation of the constitutive structure Cecconi et al. (2002). However, a variation of the parameter $\beta$ is considered which influences the slope of the critical state line in the volumetric plane which will be presented hereafter. Finally, the isotropic 
mechanism is not taken into account also due to the fact that the compression stresses are more relevant at providing the confinement of the soil at the interface level than in being directly responsible for the particle breakage observed. This can be verified by comparing the compression stress required to produce particle breakage in an isotropic compression test Hagerty et al. (1993) and the stresses found in pile experiments Jardine et al. (2013) with the possible exception of carbonate sands White and Bolton (2002).

Finally, in this proposed model, no change is considered either to the dilatancy rule nor to the slope of the critical state line in the stress space. The critical friction angle in this model is considered to be constant, similarly to that considered by Russell and Khalili (2004) and Gerolymos and Gazetas (2007).

These assumptions are obviously related to the fact that not all the conditions that affect particle damage are taken into account in the existing constitutive models (a comprehensive list of these factors is presented by Sadrekarimi and Olson (2010b)). The attempt to take all into account is not pursued here. For this reason as well, the representation of the evolution of gradation of the specimen is not attempted either.

The proposed formulation attempts to address the issue concerning grain breakage and its effects on the mechanical behaviour, stress and strains, of the soil specimens at the interface level. In order to accomplish this, two aspects must be considered: the choice of an internal variable able to reproduce the observed response in laboratory testing (reversal of the stress and volumetric trends) and the triggering mechanism for the evolution of this variable.

As it is mentioned by Sadrekarimi and Olson (2010a), as well as confirmed by other laboratory ring shear tests, particle damage is concentrated in the shear band while no particle damage is observed in the specimen outside the shear band and also that localization initiated before reaching peak shear resistance since the material was still strain-hardening. This leads to the conclusion that the particle breakage phenomena, in ring shear tests, is intrinsically linked with the formation of a shear band due to strain localization. Therefore, the search for the instability condition in geomechanics is of the essence for the formulation of a valid triggering mechanism. The shear band thickness evolution can be seen in Figure 8. The RS device used by Sadrekarimi and Olson (2010a) imposes shearing at the bottom of the specimen resulting in the formation of a shear band there as can be seen from this figure. 


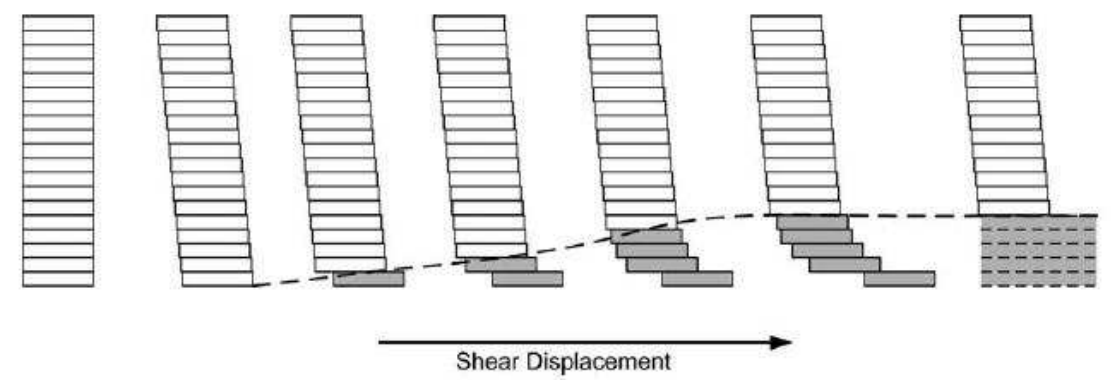

Figure 8: Shear band evolution in a RS test with shearing at the bottom of the specimen Sadrekarimi and Olson (2010a)

The localized failure mode is characterized by a shear band formation which represents a localization of strain Rice (1979). The first proposed instability criterion for standard associated materials to be the failure criteria which represents the state at which a limit value of stress is reached is considered and, therefore, unlimited deformation for a null variation in stress. This criteria is known as the Drucker's postulate Drucker (1959). However, for non-associated materials this condition fails to detect instabilities which occur before reaching the plastic limit condition (in geomechanics the best example of this is the liquefaction phenomenon). The need for this analysis leads to the second criterion presented by Hill (1958) which can predict these failures which depend on the loading path as well as the initial state of the material. This criterion is related to the sign of the second-order work and allows a local follow-up of instabilities. This condition of stability considers that a stress-strain state is considered "stable" if for any incremental stress and strain connected by the constitutive model the second-order work is strictly positive

$$
\forall(d \boldsymbol{\sigma}, d \boldsymbol{\epsilon}), \quad d^{2} W=d \boldsymbol{\sigma} \cdot d \boldsymbol{\epsilon}>0
$$

which can be written in a totally analogous way in the case of finite deformation considering the Eulerian formulation

$$
\forall\left(\boldsymbol{\sigma}^{\nabla}, \mathbf{D}\right), \quad d^{2} W=\boldsymbol{\sigma}^{\nabla} \cdot \mathbf{D}>0
$$


where $\mathbf{D}$ is the rate of deformation tensor (symmetric) and $\boldsymbol{\sigma} \nabla$ is an objective stress rate tensor.

In the case of an incrementally linear constitutive law, the positiveness of the second-order work is a sufficient condition for the uniqueness of the solution. However, when considering that the stress-strain relationship is incrementally non-linear, as in the case of elastoplasticity or fully non-linear, such as hypoplastic models, the proof is not trivial. Nevertheless, various authors have proved the positive definiteness of the elastoplastic tensor, and therefore the positivity of the second-order work is a sufficient condition for the "uniqueness of the solution" or "no loss of the stability" of the boundary problem Nova (1994). This result is true for a large class of constitutive laws, including elastoplasticity, either with an associated, or non-associated flow rule, or hypoplasticity Hamadi et al. (2008). Considering the present constitutive structure, Hamadi et al. (2008) present a general overview of the existing approaches in this domain and show the potential of the elastoplastic ECP's constitutive model to predict these failures in triaxial and biaxial loading paths for drained and undrained conditions. Finally it can be shown that bifurcation cannot occur prior to a negative second-order work as proposed by Hill (1958). For associated materials Hill's condition coincides with the bifurcation. The Hill's criterion is therefore a lower bound condition for instability states.

Hill's criterion will henceforth be taken as the triggering mechanism for the evolution of the internal variable representing the grain breakage phenomena in the constitutive model.

The internal variable to represent the mechanical behaviour of the soil under extremely high shear strains is now presented.

The monotonic deviatoric yield surface of the " $k$ " plane is given by

$$
f=q_{k}-p_{k} \cdot \sin \phi_{p p} \cdot r_{k} \cdot r_{b r_{k}} \cdot\left(1-b \cdot \ln \left(\frac{p_{k}}{p_{c}}\right)\right)=0
$$

The proposed internal variable, $r_{b r_{k}}$, is a hardening parameter of the same form as the shear hardening parameter $r_{k}$ and will evolve according to

$$
\dot{r}_{b r_{k}}=-\dot{\Lambda}\left(a^{b r} \cdot r_{b r_{k}}\right)
$$



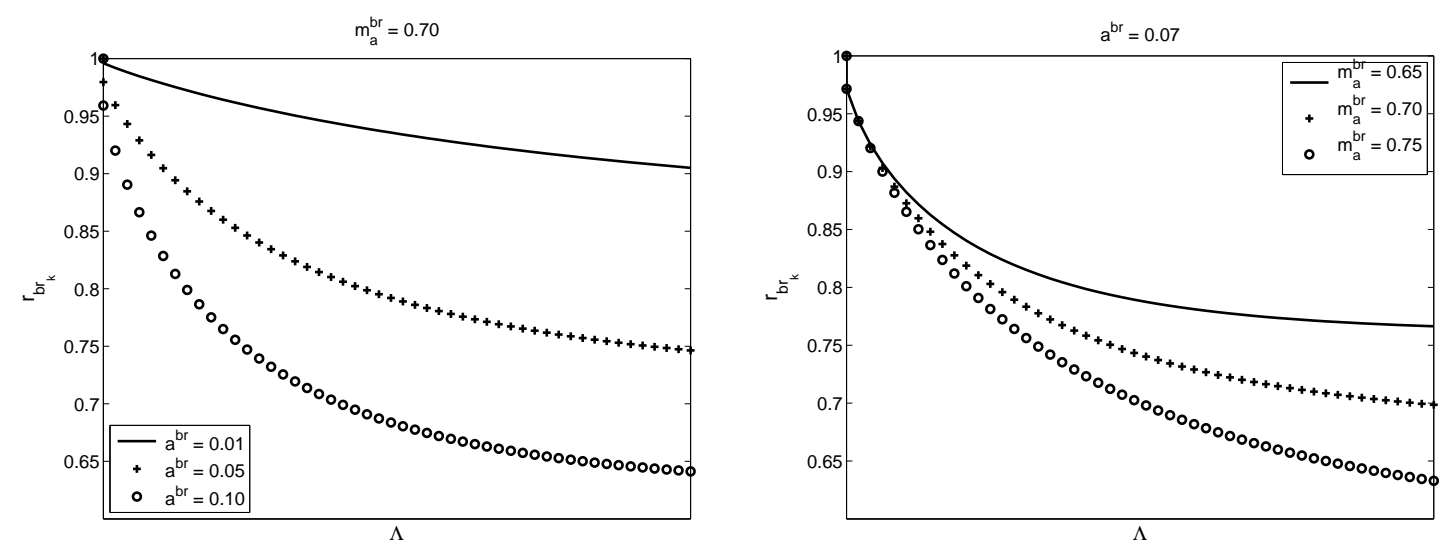

Figure 9: Evolution of $r_{b r_{k}}$

The variable $r_{b r_{k}}$ will evolve from its initial value which is unity $(=1)$ and decrease asymptotically to zero with the increase of deviatoric plastic strain. This progression was chosen for it works best in representing the behaviour of the soil specimen as was observed from laboratory test results. The key parameter for the evolution of this variable is the parameter $a^{b r}$. The evolution for the parameter $a^{b r}$ is here considered as

$$
a^{b r}=a_{0}^{b r}-\left[\left(1-r_{b r_{k}}\right) \cdot a_{0}^{b r}\right]^{m_{a}^{b r}}
$$

The parameter $m_{a}^{b r}$ allows the user an extra control over the rate of the evolution of parameter $a^{b r}$ to account for variability of different soil types with respect to breakage. Both the magnitude and the evolution of the breakage mechanism are "controlled" by these parameters in the stress space and, moreover, influence the volumetric plane indirectly. These parameters represent, therefore, a general approach to simulate the various factors in soils that influence breakage Sadrekarimi and Olson (2010b).

The evolution of these parameters is shown graphically in Figure 9 and the influence of the internal variable $r_{b r_{k}}$ on the yield surface can be seen in Figure 10.

Figure 11 shows the magnitude and direction of plastic deformation increments in the revised ECP model for an undrained shear test. The vectors of plastic volumetric deformation reverse direction at both phase transfor- 


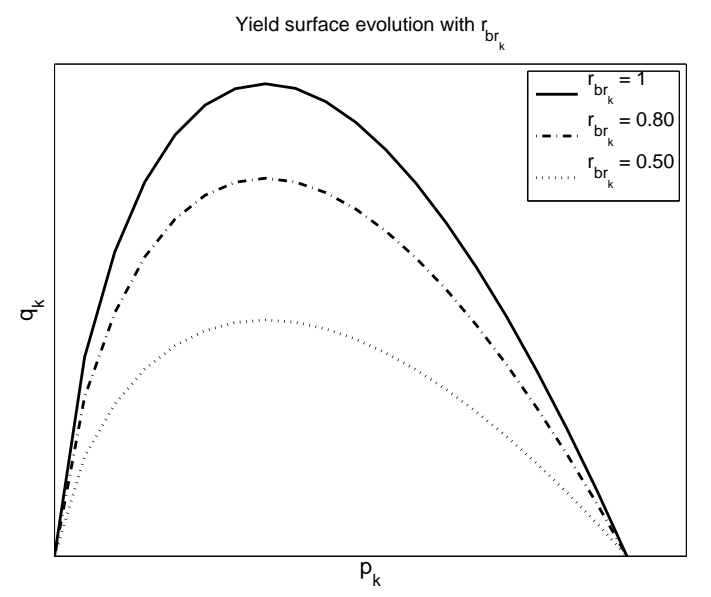

Figure 10: Yield function variation with the evolution of $r_{b r_{k}}$

mation points while the deviatoric plastic deformation vector never changes direction.

Concerning the compressibility of the specimen, it was shown from results in ring shear tests and from pile installation tests that the critical state line in the volumetric plane for specimens subjected to particle damage was not properly defined. In fact, Sadrekarimi and Olson (2011a) among others showed the different CSL's for "uncrushed" and "crushed" sands and how they differed. One cannot fail to notice the different angle of the slope of the CSL (results from Sadrekarimi and Olson (2011a) show 62\% and 38\% variation in the angle for OT and IR sand, respectively) as well as its global position. While its position has been somewhat addressed by the introduction of the variable $r_{b r_{k}}$, its slope concerns the variable $\beta$ in the ECP constitutive model. To properly represent this phenomena the variable $\beta$ is made to have an evolution law related with plastic work $W^{p}$ which results in

$$
\beta=\beta_{0} \frac{b_{W_{p}}}{\left(b_{W_{p}}+W_{p}\right)}
$$

where $\beta_{0}$ is the initial value of $\beta$ which represents the slope of the "uncrushed" CSL. The parameter " $b_{W_{p}}$ " is given by the user and represents the plastic work the soil has to undergo before significant change in the CS locus happens. The validity of this evolution relationship, however, cannot be demonstrated due to lack of laboratory evidence to properly define its evo- 

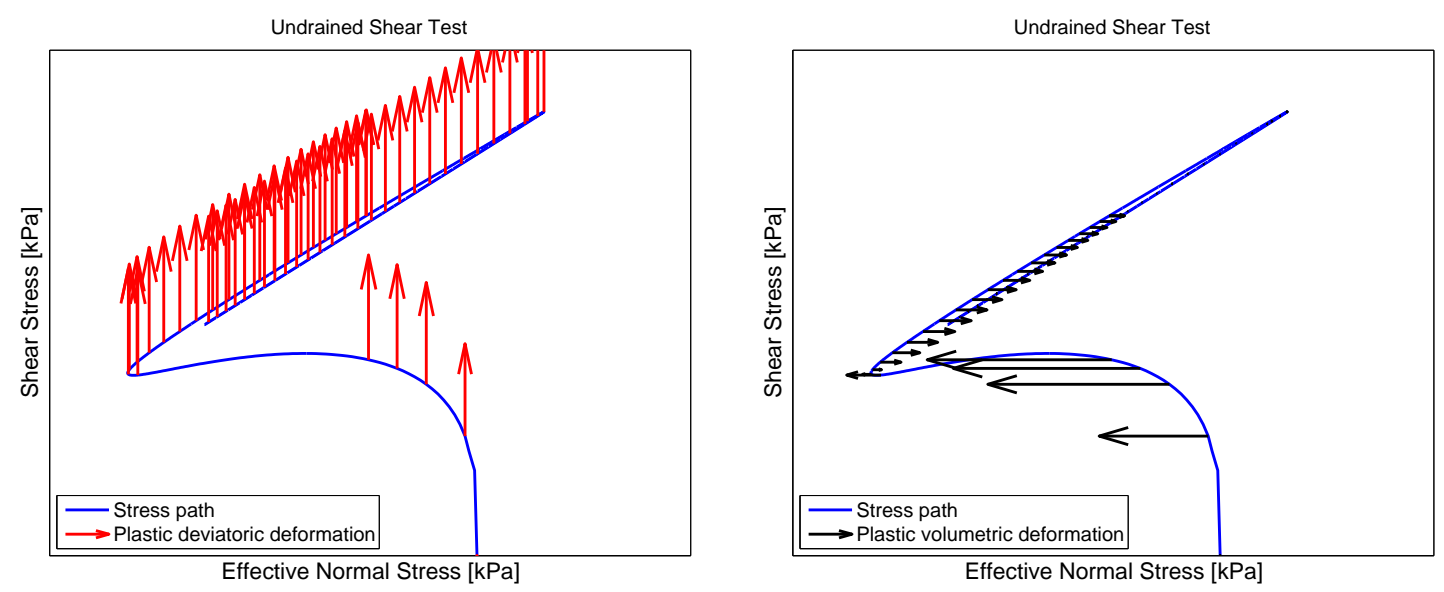

Figure 11: Vectors of plastic deformation during loading representing the non-associated flow rule for the revised model

lution since only the initial and final values of $\beta$ are known.

The ECP constitutive model is therefore enhanced to better represent the behaviour of sand specimens subjected to extreme shearing. This constitutive model allows for the simulation of the second phase transformation that has been observed in laboratory testing by some authors in large displacement shear resistance tests and to accurately represent the stress-strain relationship even at very high deformations. Also, the determination of a critical state line at a different position in the volumetric space and dependent on the stress path is possible considering this constitutive structure. Without loss of generality, the proposed constitutive structure can be applied to interface models such as Aubry et al. (1990), D'Aguiar et al. (2009) and D'Aguiar et al. (2011).

\section{Validation and other applications}

The tests modelled in this section consist of undrained (constant volume), a constant normal stiffness and a constant normal load tests. The numerical model results of the undrained tests are compared to the laboratory test results in order to validate it both quantitatively and qualitatively. 
The constant normal stiffness test and its relevance to the soil-pile interface behaviour is also discussed. The most relevant trends of soil behaviour during a shear test performed to very large strains are shown to be represented by the proposed constitutive relationship. Also, the response of the original constitutive model is represented in order to show the influence of the new internal variable on the behaviour.

According to the vertical boundary conditions RS tests can be divided in three different types corresponding to a system represented by $d \sigma_{n}=\frac{K}{t} d u_{n}$ where $t$ is the thickness of the interface and $\mathrm{K}$ represents its stiffness:

Case I: Constant normal load test (CNL test) in which $K=0, d \sigma_{n}=0$, $d u_{n} \neq 0$ (similar to "drained conditions"),

Case II: Constant normal volume test (CV test) in which $K=\infty, d \sigma_{n} \neq$ $0, d u_{n}=0$ (similar to "undrained conditions"),

Case III: Constant normal stiffness test (CNS test) in which $K=c s t, d \sigma_{n}$ $\neq 0, d u_{n} \neq 0$.

In this section the performance of the model and the influence of the grain crushing mechanism are studied by modeling ring shear tests as a boundary value problem where a localized shear band is generated. On one hand, real tests are simulated numerically and the obtained results are compared to those measured during the experiment to validate qualitatively and quantitatively the model. On the other hand, different boundary conditions, similar to those encountered in the soil in different configurations are simulated to study the effect of this mechanism on the shear stresses and therefore its shear resistance.

We will first model the undrained RS tests (CV test) performed on Ottawa (OT) and Illinois River (IR) sands by Sadrekarimi and Olson (2010b). Unfortunately, their drained (CNL) tests cannot be used as some incoherences are observed due to rotation of the lever arm. The simulated tests are described in Table 1.

The model parameters identification has been the subject of several papers using different strategies such as constrained optimization procedure Cekerevac et al. (2006) or the definition of correlations Hicher and Rahma (1994). We have used the strategy developed at ECP (Lopez-Caballero et al. (2003) Lopez-Caballero et al. (2007) Hicher (2011)) and already applied to 
several materials (D'Aguiar et al. (2011) Gomes (2013)). The presentation of this strategy is out of the scope of this paper and we will recall only the important points. The model parameters can be classified differently depending on ones objective. As the model is a plastic one, a preliminary classification of evident parameters is:

- Elasticity parameters $K, G, n_{e}, p_{\text {ref }}$

- Plasticity and critical state parameters $\phi_{p p}, \beta, b, d$

- Hardening parameters

$$
\begin{aligned}
& \text { Shear mobilization } a_{1}, a_{2}, m \\
& \text { Volumetric strain } \psi, a_{\psi}, c_{1}, c_{2} \\
& \text { Breakage parameters } \quad a^{b r}, m_{a}^{b r}, b_{W_{p}}
\end{aligned}
$$

- Initial state parameter $p_{c 0}$

Among the above parameters there are those which are directly measured from the quantitative analysis of observed results, such as parameters of elasticity and perfect plasticity. There are also the parameters which are not directly measurable and which must be obtained through calibration. For the breakage mechanism only parameters which cannot be directly measured are introduced in the model and therefore should be identified by calibration. Given the nonlinear character of the model and the high number of parameters, there is a risk not to obtain a single set of parameters after calibration, especially if only one type of stress path is considered. Using correlations and understanding the physical model and its parameters is the only way to ensure proper calibration. To do this, we must add that the mechanisms are directly related to the loading path experienced by the soil. In practice, different types of tests are performed in the laboratory to characterize soils. They concern essentially triaxial compression or extension or shear tests under drained or undrained conditions. Resonant column tests are performed for geotechnical earthquake engineering applications where small strains prevail. For the application in which the present model is developed, drained or undrained triaxial and shear tests can be used to calibrate most of the parameters. However, some large strain shear tests are necessary for the calibration of the breakage mechanism parameters. The model parameters are summarized in the Appendix B of the paper. 


\begin{tabular}{|l|c|c|c|c|}
\hline \multicolumn{2}{|c|}{ Laboratory tests (Undrained RS tests) } & \multicolumn{2}{c|}{ Void ratios } \\
\hline Sand & Effective consolidation stress [kPa] & Relative Density [\%] & $e_{\min }$ & $e_{\max }$ \\
\hline OT sand & 217 & 26 & & \\
OT sand & 279 & 24 & 0.391 & 0.679 \\
OT sand & 29 & 23 & & \\
\hline IR sand & 646 & 28 & & \\
IR sand & 541 & 29 & 0.464 & 0.757 \\
IR sand & 553 & 35 & & \\
\hline \hline
\end{tabular}

Table 1: Laboratory tests details from Sadrekarimi and Olson (2011a)

The geometrical and mechanical configuration of the hollow cylinder shear test simulated numerically is given in Figure 12. Assuming no radial soil displacement due to rigid lateral rings a double (radial and angular) plane strain simple shear condition is obtained. Moreover, one should not forget the radial non-uniformity of the stresses and shear strain which is however reduced due to the radial thickness of the apparatus (the ratio of outer to inner ring diameter is 1.33, resulting in an error of less than $2 \%$ at the peak shear stress due to strain nonuniformity Sadrekarimi and Olson (2010a)). Though, a precise analysis of the test results implies a 3D model, thanks to the double plane strain assumption, the resultant vertical load and torque can be computed as the sum of the resultant forces and moments on a series of radial slices in which the normal and shear stresses can be considered constant.

The enhanced model was implemented in the GEFDyn finite element code and the boundary value problem considering a radial slice of one radian was modeled. As no specific method of regularization is used to circumvent the mesh dependence when shear strain localizes, the size of the elements is chosen to be equal to the shear band thickness observed in the specimen during the laboratory testing. The height of the shear band must, therefore, be considered as a known parameter.

The results are analyzed at different heights presented in the Figure as $z_{i}$. The mesh cannot deform in the vertical direction due to the boundary conditions imposed to replicate the no-volume-change condition of the tests. An imposed displacement (shear in the $\theta$ axis) is applied on the bottom element of the mesh which will result in the localization of deformation in that element. This is consistent with the laboratory results. The shear band is always located where shear is imposed Sadrekarimi and Olson (2011a). 


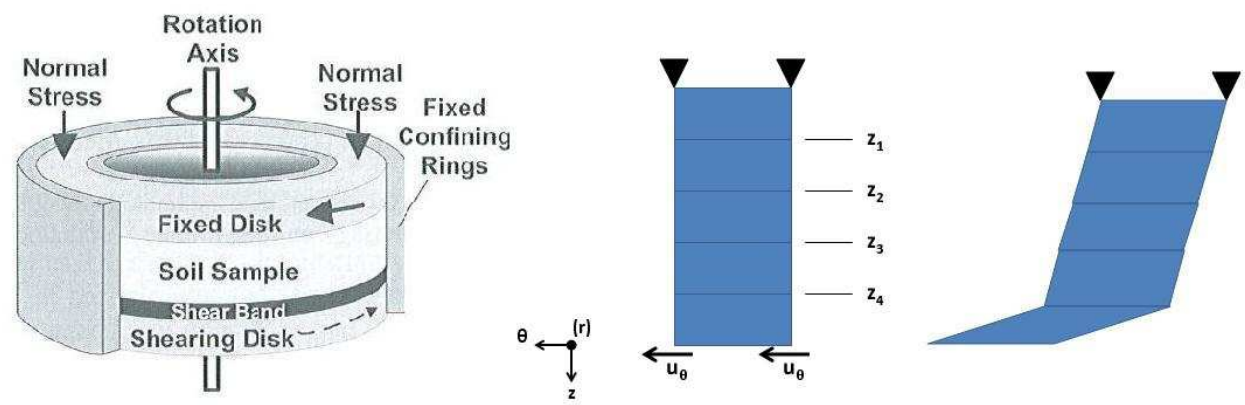

Figure 12: RS test device Sadrekarimi and Olson (2010a) and the finite element mesh for the numerical simulation

The model is axisymmetric and, therefore, the cylindrical coordinate system $(\mathrm{r}, \theta, \mathrm{z})$ is considered. The velocity vector and rate of deformation tensor can therefore be defined for this problem as such:

$$
\begin{gathered}
\mathbf{v}=v_{\theta}(z) r \mathbf{e}_{\theta}+v_{z}(z) \mathbf{e}_{z} \\
\mathbf{D}=r \frac{\partial v_{\theta}}{\partial z} \mathbf{e}_{\theta} \otimes \mathbf{e}_{z}+\frac{1}{2} \frac{\partial v_{z}}{\partial z} \mathbf{e}_{z} \otimes \mathbf{e}_{z}
\end{gathered}
$$

- Discussion and Results

The results from the RS tests are analyzed considering two different final strain levels at the shear band. In terms of volumetric variation the results are validated considering the two critical state lines, "crushed and uncrushed", at very high shear strains (see Sadrekarimi and Olson (2011a)). The measurements in the stress space and shear strains to stress are analyzed considering lower ranges of strain (in the order of $20 \mathrm{~cm}$ of displacement at the bottom). This simulation (Figures 13 and 14) shows the ability of the proposed constitutive model to replicate both the "critical state line" at usual shear strain levels known in geotechnical testing and at an extreme shear strain value where the breakage mechanism has a predominant role. These results imply that the critical state (deformation at constant volume) is much further away 


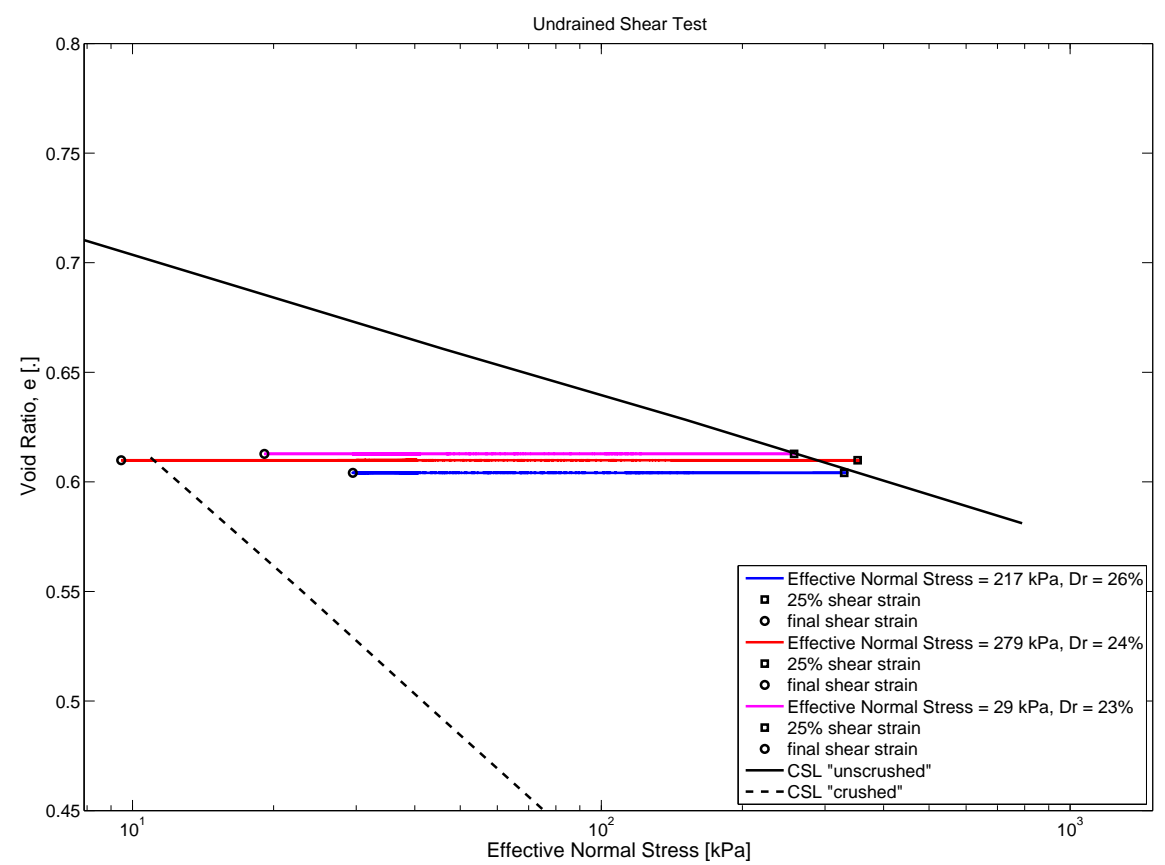

Figure 13: $\sigma_{n}^{\prime}-e$ (void ratio) with critical state lines from Sadrekarimi and Olson (2011a) for Ottawa sand

in terms of strain than the model predicts. This formulation allows for the capture of the observed behaviour of the soil specimen at high shear strains. The change in the slope of the critical state line from the "uncrushed" to the "crushed" state is also taken into account by means of the evolution in the parameter $\beta$.

Note that the proposed model is indeed capable of reproducing the stressstrain relation at very high strains which follows and inversed hyperbolashaped curve. Figure 15 shows the evolution of normal and shear stresses during an undrained RS test of IR sand for a vertical stress of $334 \mathrm{kPa}$ with tangential displacement represented in a logarithmic scale.

The stress planes are now analyzed with results from undrained RS tests on Ottawa sand. Figures 16 and 17 show the evolution of stresses and plastic volumetric variation (at different heights of the mesh) during the simulated undrained shear test. Note that $\dot{J}^{p}$ is the plastic variation of the Jacobian 


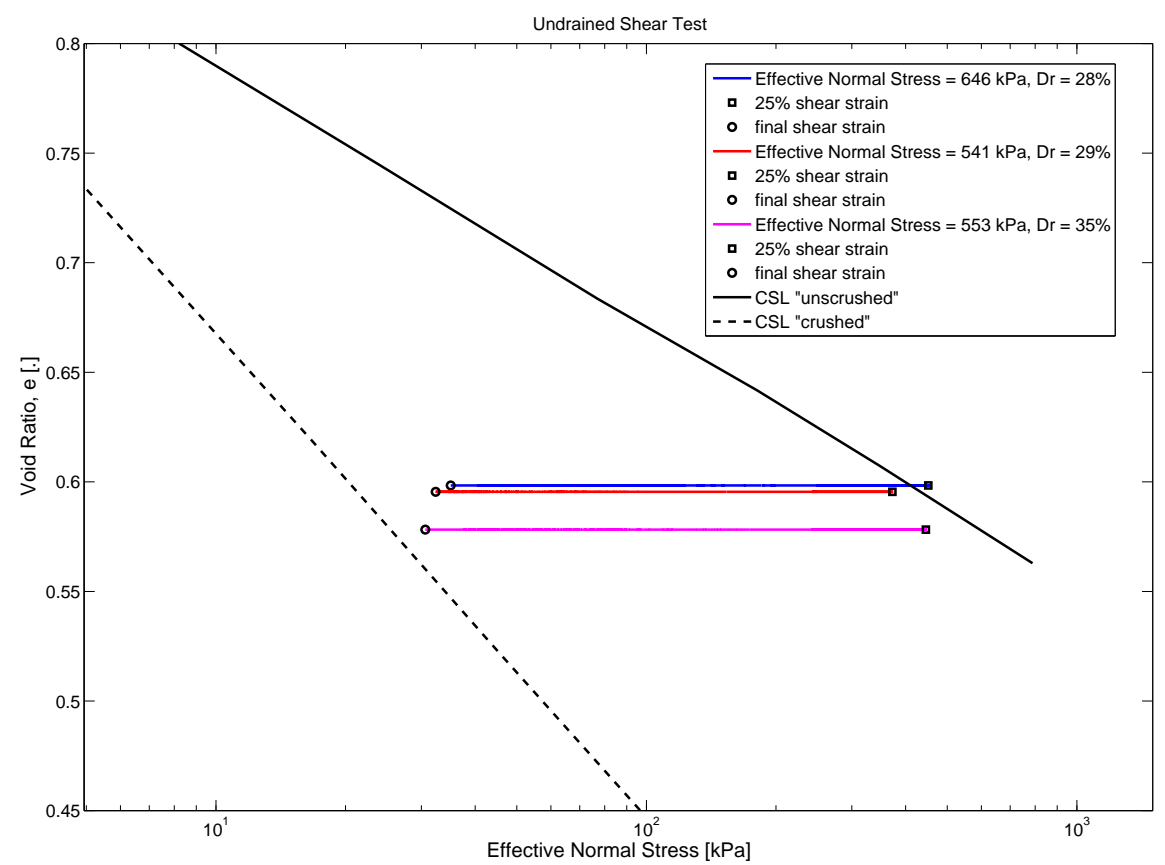

Figure 14: $\sigma_{n}^{\prime}-e$ (void ratio) with critical state lines from Sadrekarimi and Olson (2011a) for Illinois River sand

where $J=\operatorname{det} \mathbf{F}$. Three lines are present in the Figures which correspond to the laboratory results found by Sadrekarimi and Olson (2010b) the results from the original model and those of the proposed model. When considering an undrained RS test, the variation of the normal stress is "controlled" by the elastic volumetric deformation of the specimen which will in turn determine the increase or decrease of the effective normal stress. The plastic volumetric variation of the specimen can be seen in Figure 17. This Figure clearly shows that the proposed constitutive formulation successfully reproduces the second phase transformation point in the shear band when the behaviour switches, from dilation to contraction, that was observed in laboratory tests while the original formulation does not. Note that despite continuity of stresses there is discontinuity of strains in the specimen as a result of localization. The different volumetric behaviours found are consistent with the laboratory data where the second phase transformation is only seen in the shear band where 

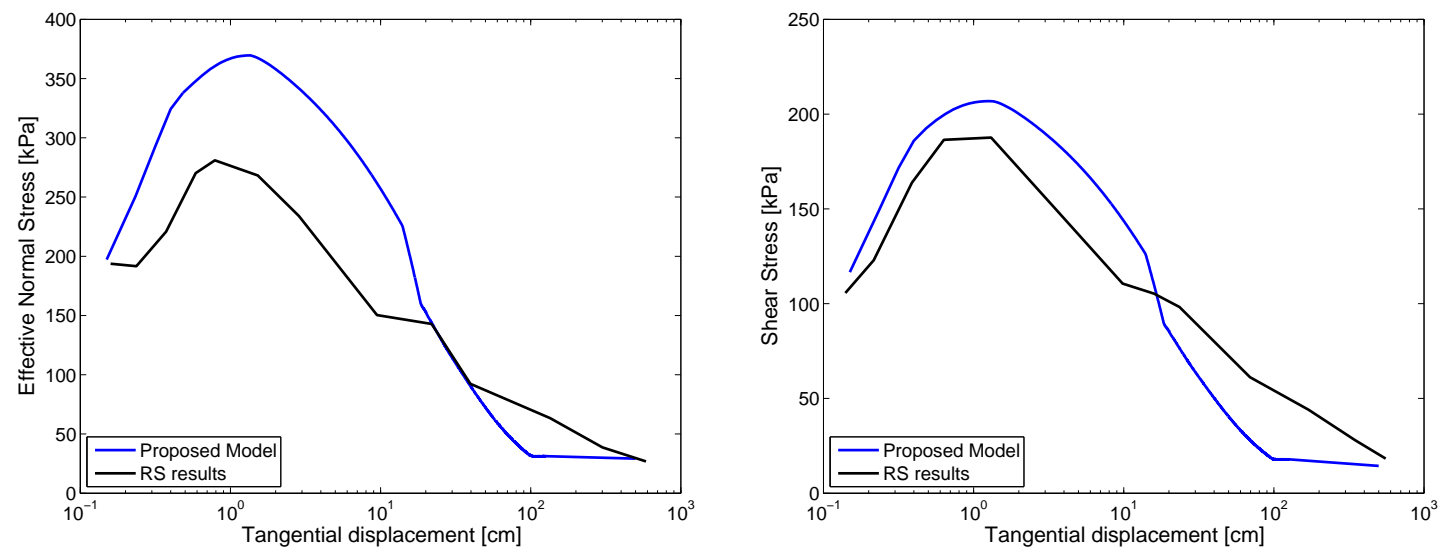

Figure 15: Illinois River sand : $u_{T}-\sigma_{n}^{\prime}$ and $u_{T}-\tau$

particle breakage is found to occur. The discontinuity in displacements can be seen also in Figure 18 where the tangential and normal displacements for each section of the specimen are shown (the shear band is left out due to reasons of scale). Note that once localization occurs no tangential displacement is observed since shear strains are only developing at the shear band just as the experimental data show. The dilation at these levels is a result of the constant volume condition of the test imposed by the boundary conditions since the shear band is contracting.

The second phase transformation can be seen also clearly in the stress plane in Figure 16. Sadrekarimi and Olson (2010a) describes this as competing shearing mechanisms which are found to be at play: dilation and particle damage (contractive behaviour) usually starting with dilation in a more important role leading to a shear resistance increase until the second phase transformation and finally ending with net contraction due to particle damage and decrease in shear resistance until reaching the critical state. Laboratory tests show that once in the stress space, the loading path reaches the critical state line (CSL) the ratio between the shear and normal stress does not change, thus, the stress path does not deviate from the CSL. The proposed constitutive relation is accurate in simulating this behaviour. Similar trends are found for Illinois River (IR) sand in undrained shear and the results are presented in the Appendix $\mathrm{C}$ of this paper. 

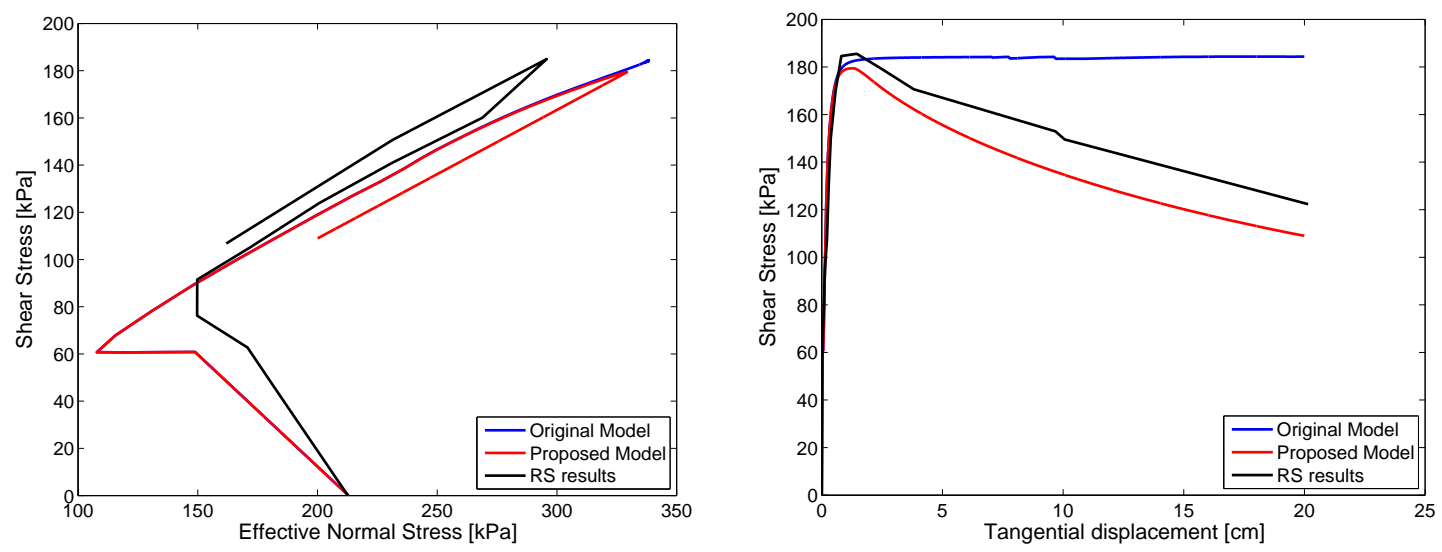

Figure 16: Ottawa sand : $\sigma_{n}^{\prime}-\tau$ and $u_{T}-\tau$

In the Figures presented above the captions show $u_{t}$ and not the shear strain as it is usually the norm in presenting these curves. This is due to the fact that the definition of strain in finite deformation is not straightforward and the sum of the increments of the tensor $\mathbf{D}$ has no direct physical meaning as total strain.

Finally, note that the criteria for the activation of the evolution of the breakage parameter is verified in the stress paths for both sands. However, results from other RS tests and for tests with different stress paths have been found to show particle breakage (results from Okada et al. (2005) are an example of that). To consider the triggering mechanism proposed herein would be erroneous to simulate those findings. The need and choice of the triggering mechanism is brought into question. A possible solution is to consider the mechanism active from the start of loading (as the constitutive models presented by Cecconi et al. (2002), Salim and Indraratna (2004) and $\mathrm{Hu}$ et al. (2011), among others) meaning that an evolution of the gradation curve exists even at relatively small strains.

The constant volume condition is the equivalent of considering an infinite constant normal stiffness (CNS) condition. This is not, however, the case at the soil-pile interface but can be encountered during landslides in saturated soil. In that case the normal stress represents the effective normal stress and its variation is equivalent to the pore water pressure. The stiffness imposed 

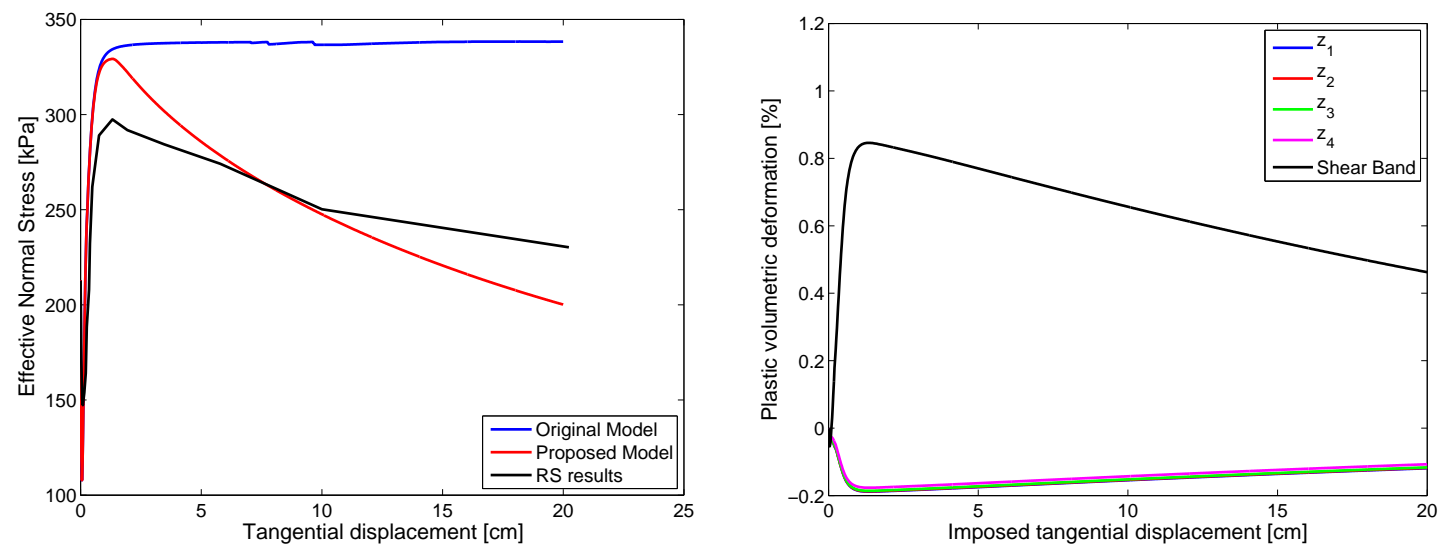

Figure 17: Ottawa sand : $u_{T}-\sigma_{n}^{\prime}$ and $u_{T}-\dot{J}^{p}$

by the soil at the interface of the pile is finite (albeit very high) and the results will differ due to this. A RS test with a CNS condition might, therefore, be a better representation of the loads applied to the soil at the pile interface level. The CNS condition is achieved in finite element modelling by placing an elastic element with a given stiffness on the bottom of the model. The stiffness considered is of $2.96 \mathrm{MPa}$ (bulk modulus) and the constitutive model of the specimen is that of OT sand. The constant normal load boundary condition (CNL) is also here considered in order to define both limit boundary conditions for a simple shear test - constant volume and constant normal load. The CNL test consists of shearing without any displacement condition at the bottom of the specimen while maintaining a constant normal load. The results for the three test types are presented here and the results compared.

The stress and strain paths shown are typical of a shearing test for each respective boundary condition (Figures 19 and 20). Note that the critical state line in stress space is verified by all tests and that the second phase transformation is found to occur at the same level of tangential displacement as well. However, in terms of stress the second phase transformations occurs at different intervals as a result of the different boundary conditions. In the CNS and CNL cases, because dilation is not restricted by a rigid boundary condition, it allows for higher volumetric expansion of the specimen (Figure 20). Also, the evolution of crushing is shown to vary in magnitude for 


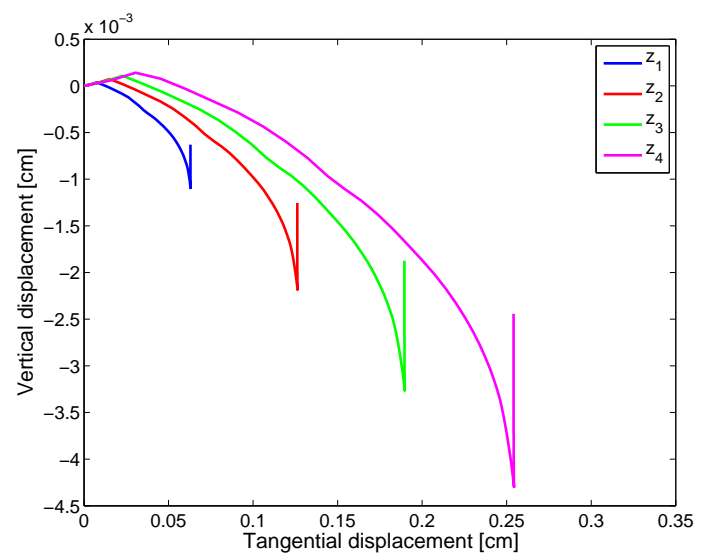

Figure 18: $u_{t}-u_{n}$

each test. The degradation of the specimen, represented by the plastic volumetric variation, has a higher gradient in relation to the imposed tangential displacement for both the CNS and CNL tests than at the constant volume test. Not only the gradient but also the total contraction of plastic volumetric deformation is found to be higher in the CNL and CNS cases than the constant volume case. Similar results were found in laboratory testing (Okada et al. (2005) and Sadrekarimi and Olson (2010b)) when comparing undrained and drained tests. It was found that there was considerably more contractive volume change in drained tests than in undrained tests due to grain breakage. This trend is also observed in the simulation performed here. Since the CNS condition is an intermediate case between perfectly drained and undrained conditions it is only logical that more crushing is found in CNS test than constant volume tests. 

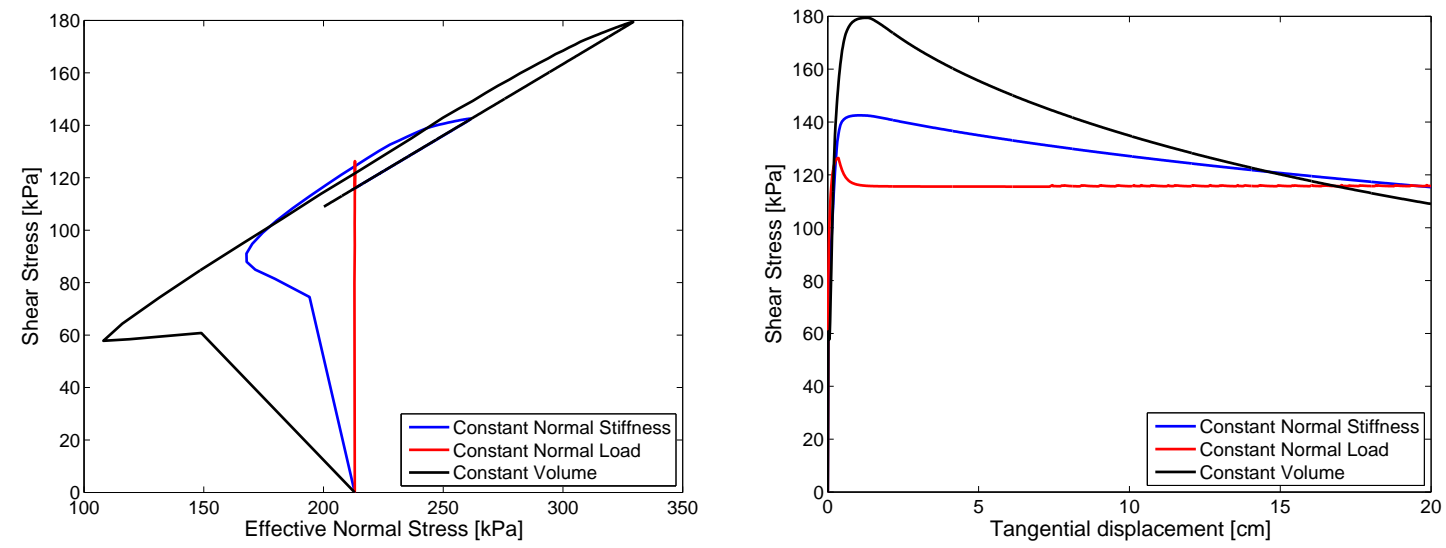

Figure 19: Ottawa sand : $\sigma_{n}^{\prime}-\tau$ and $u_{T}-\tau$
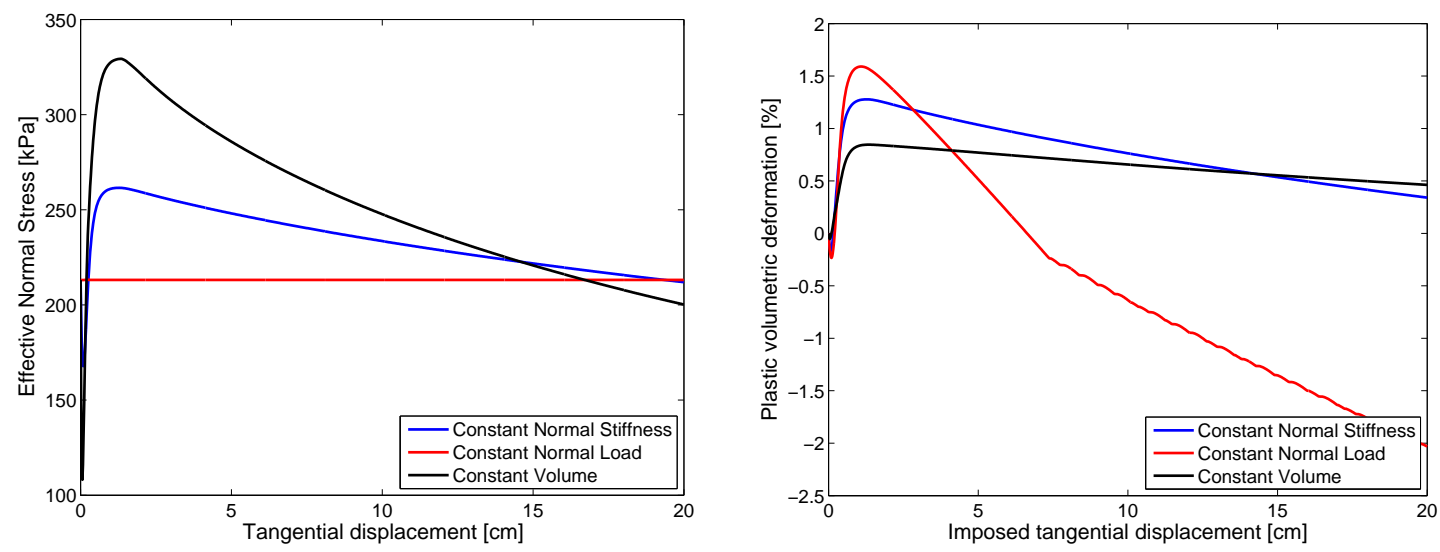

Figure 20: Ottawa sand : $u_{T}-\sigma_{n}^{\prime}$ and $u_{T}-j^{p}$ 


\section{Conclusions}

This work focused on modelling the behaviour of granular cohesionless soil subjected to large shear strains. First, the finite deformations that occur when considering large transformations in solid mechanics are addressed by adopting the solution proposed by Xiao et al. (1997). The adoption of the logarithmic rate in the constitutive equations allows the resolution of the common issues present with finite deformation calculations. As long as the behaviour of the soil is concerned, laboratory test results show similarities between ring shear tests and the soil behaviour at the soil-pile interface Yang et al. (2010) or at a slope slip-surface Gerolymos and Gazetas (2007) during shearing. In the case of piles this is specially verified during installation (displacement piles) where the neighbouring material is subjected to extremely high shear strains. Grain breakage is shown to be present in both cases with similar effects on shear mobilization controlled by volumetric behaviour.

Then, a revised version of a constitutive model is proposed to address the physical phenomena which take place at high shear strains. The critical state concept and dilatancy rule have been conserved. However, thanks to the modification of the yield function and the introduction of an additional internal variable which characterizes the irreversibility due to grain crushing, the second transformation phase is obtained resulting in the modification of the critical state line in the void ratio-stress plane. The proposed internal variable and its evolution rule, as well as the triggering mechanism based on the detection of the beginning of instability, when integrated in an existing constitutive model, from the ECP elastoplastic constitutive models family, are shown to be successful in simulating the stress-strain relationship in ring shear tests. Constant volume, constant normal load and constant normal stiffness conditions were applied to highlight the capability of the model to capture interface non-linear behaviour for different stress paths. The mechanism introduced to the model can without lack of generality be applied to the other ECP elastoplastic constitutive models family based on the same theoretical and physical principles.

\section{References}

D. Aubry, J. C. Hujeux, F. Lassoudire, Y. Meimon, A double memory model with multiple mechanisms for cyclic soil behavior., in: International Symposium on Numerical Methods in Geomechanics, 3-13, 1982. 
J. C. Hujeux, A critical state type stressstrain law for monotonous and cyclic loading., in: Symposium on Implementation of Computer Procedures and StressStrain Laws in Geot, Chicago, 3-13, 1982.

H.-C. Wu, Continuum mechanics and plasticity, Chapman and Hall, 2005.

H. Xiao, O. Bruhns, A. Meyers, Elastoplasticity beyond small deformations., Acta Mechanica 182 (2006) 31-111.

E. de Souza, D. Peric, D. Owen, Computational methods for plasticity. Theory and Applications, Wiley, 2008.

G. Johnson, D. Bammann, A discussion of stress rates in finite deformation problems., International Journal of Solids and Structures 20 (8) (1984) $725-737$.

C.-S. Liu, H.-K. Hong, Non-oscillation Criteria for Hypoelastic Models under Simple Shear Deformation., Journal of Elasticity 57 (1999) 201-241.

C. Liangsen, Z. Xinghua, F. Minfu, The simple shear oscillation and the restrictions to elastic-plastic constitutive relations., Applied Mathematics and Mechanics 20 (6) (1999) 593-603.

H. Xiao, O. Bruhns, A. Meyers, Logarithmic strain, logarithmic spin and logarithmic rate., Acta Mechanica 124 (1997) 89-105.

H. Xiao, O. Bruhns, A. Meyers, A consistent finite elastoplasticity theory combining additive and multiplicative decomposition of the stretching and the deformation gradient., International Journal of Plasticity 16 (2000) $143-177$.

O. Bruhns, H. Xiao, A. Meyers, Large simple shear and torsion problems in kinematic hardening elasto-plasticity with logarithmic rate., International Journal of Solids and Structures 38 (2001) 8701-8722.

A. Meyers, O. Bruhns, H. Xiao, Objective stress rates in repeated elastic deformation cycles., in: PAMM Proc. Appl. Math. Mech, 249-250, 2005.

R. Naghdabadi, M. Yeganeh, A. Saidi, Application of corotational rates of the logarithmic strain in constitutive modeling of hardening materials at finite deformations., International Journal of Plasticity 21 (2005) 1546-1567. 
J. Simo, K. S. Pister, Remarks on rate constitutive equations for finite deformation problems: Computational implications., Comput. Meth. Appl. Mech. Engng 46 (1984) 201-215.

O. Bruhns, H. Xiao, A. Meyers, Self-consistent Eulerian rate type elastoplasticity models based upon the logarithmic stress rate., Int. J. Plasticity 15 (1999) 479520.

Y. Dafalias, A missing link in the macroscopic constitutive formulation of large plastic deformations., In: Plasticity today, modelling, methods and applications (1985) 135151.

C. Truesdell, Hypo-elasticity, J. Rat. Mech. Anal. 4 (1955) 83-133.

A. Green, P. Naghdi, Some remarks on elastic-plastic deformation at finite strain, Int. J. Engng Sci. 9 (1971) 1219-1229.

P. Naghdi, A critical review of the state of finite plasticity, ZAMP 41 (1990) $315-394$.

J. Fish, K. Shek, Finite deformation plasticity based on the additive split of the rate of deformation and hyperelasticity., Comput Methods Appl Mech Eng 190 (2000) 75-93.

J. Chakrabarty, Theory of plasticity, Butterworth-Heinemann, 2006.

Y. Okada, K. Sassa, H. Fukuoka, Undrained shear behaviour of sands subjected to large shear displacement and estimation of excess pore-pressure generation from drained ring shear tests., Canadian Geotechnical Journal 42 (2005) 787-803.

B. Lehane, D. White, Lateral stress changes and shaft friction for model displacement piles in sand., Canadian Geotechnical Journal 42 (4) (2005) 1039-1052.

D. White, M. Bolton, Observing friction fatigue on a jacked pile., in: International Workshop on Constitutive and Centrifuge Modelling: Two Extremes, Monte Verita, Switzerland, 2002.

D. White, M. Bolton, Displacement and strain paths during plane-strain model pile installation in sand., Géotechnique 54 (6) (2004) 375-397. 
S. D’Aguiar, F. Lopez-Caballero, A. Modaressi-Farahmand-Razavi, J. Santos, Piles under cyclic loading: study of the friction fatigue and its importance in piles., in: 17th International Conference on Soil Mechanics and Geotechnical Engineering, Egypt, Alexandria, 1313-1316, 2009.

Z. X. Yang, R. J. Jardine, B. T. Zhu, P. Foray, C. H. C. Tsuha, Sand grain crushing and interface shearing during displacement pile installation in sand., Géotechnique 60 (6) (2010) 469-482.

A. Sadrekarimi, S. Olson, Critical state friction angle of sands., Géotechnique 61 (9) (2011a) 771-783.

K. Sassa, H. Fukuoka, G. Wang, N. Ishikawa, Undrained dynamic-loading ring-shear apparatus and its application to landslide dynamics., Landslides 1 (2004) 7-19.

A. Sadrekarimi, S. Olson, Shear Band Formation Observed in Ring Shear Tests on Sandy Soils., Journal of Geotechnical and Geoenvironmental Engineering 136 (2) (2010a) 366-375.

A. Sadrekarimi, S. Olson, Particle damage observed in ring shear tests., Canadian Geotechnical Journal 47 (2010b) 497-515.

A. Sadrekarimi, S. Olson, Yield strength ratios, critical strength ratios, and brittleness of sandy soils from laboratory tests., Canadian Geotechnical Journal 48 (2011b) 493-510.

C. S. Desai, Y. Ma, Modelling of joints and interfaces using the disturbed state concept., International Journal for Numerical and Analytical Methods in Geomechanics 16 (1992) 623-653.

G. Mortara, M. Boulon, V. N. Ghionna, A 2-D constitutive model for cyclic interface behaviour., International Journal for Numerical and Analytical Methods in Geomechanics 26 (11) (2002) 10711096.

V. D. Gennaro, R. Frank, Elasto-plastic analysis of the interface behaviour between granular media and structure., Computers and Geotechnics 29 (2002) 547-572. 
M. Cecconi, A. DeSimone, C. Tamagnini, G. Viggiani, A constitutive model for granular materials with grain crushing and its application to a pyroclastic soil., International Journal for Numerical and Analytical Methods in Geomechanics 26 (2002) 1531-1560.

A. Russell, N. Khalili, A bounding surface plasticity model for sands exhibiting particle crushing., Canadian Geotechnical Journal 41 (2004) 1179 1192.

K. H. Roscoe, A. N. Schofield, C. P. Wroth, On the yielding of soils., Géotechnique 8 (1) (1958) 22-53.

W. Salim, B. Indraratna, A new elastoplastic constitutive model for coarse granular aggregates incorporating particle breakage., Canadian Geotechnical Journal 41 (2004) 657-671.

W. Hu, Z. Yin, C. Dano, P.Y.Hicher, A constitutive model for granular materials considering grain breakage., Science China - Technological Sciences 54 (8) (2011) 21882196.

J. Biarez, P. Y. Hicher, Elementary Mechanics of Soil Behaviors, Balkema, ROTTERDAM, 1994.

A. Modaressi, Dossier d'Habilitation Diriger des Recherches, Hdr, Ecole Centrale Paris, 2003.

A. Daouadji, P.-Y. Hicher, A. Rahma, An elastoplastic model for granular materials taking into account grain breakage., Eur. J. Mech. A/Solids 20 (2001) 113137.

S. Sica, L. Pagano, A. Modaressi, Influence of past loading history on the seismic response of earth dams., Computers and Geotechnics 35 (2008) $61-85$.

P. V. Lade, L. B. Ibsen, A study of the phase transformation and the characteristic lines of sand behaviour., in: Symposium on Deformation and Progressive Failure in Geomechanics, Nagoya, Japan, 1997.

R. Hill, A general theory of uniqueness and stability in elastic-plastic solids, J. Mech. Phys. Solids 6 (1958) 236-249. 
I. Einav, Soil mechanics: breaking ground., Phil. Trans. R. Soc. A 365 (2007) 2985-3002.

M. M. Hagerty, D. R. Hite, C. R. Ullrich, , D. J. Hagerty, One-Dimensional High-Pressure Compression of Granular Media., Journal of Geotechnical Engineering 119 (1) (1993) 1-18.

G. R. McDowell, M. D. Bolton, D. Robertson, The fractal crushing of granular materials., J. Mech. Phys. Solids 44 (12) (1996) 2079-2102.

R. J. Jardine, B. T. Zhu, P. Foray, Z. X. Yang, Measurement of stresses around closed-ended displacement piles in sand., Géotechnique 63 (1) (2013) 1-17.

N. Gerolymos, G. Gazetas, A model for grain-crushing-induced landslidesApplication to Nikawa, Kobe 1995., Soil Dynamics and Earthquake Engineering 27 (2007) 803-817.

J. R. Rice, The localization of plastic deformation., Theoretical and Applied Mechanics, Koiter WT (1979) 207-220.

D. C. Drucker, A definition of stable inelastic material., J. Appl. Mech. 26 (1959) 101-186.

R. Nova, Controllability of the incremental response of soil specimens subjected to arbitrary loading programmes., Journal of the Mechanical Behaviour of Materials 5 (2) (1994) 193-203.

K. Hamadi, A. Modaressi-Farahmand-Razavi, F. Darve, Bifurcation and instability modelling by a multimechanism elasto-plastic model., International Journal for Numerical and Analytical Methods in Geomechanics 32 (2008) 461-492.

D. Aubry, A. Modaressi, H. Modaressi, A constitutive model for cyclic behaviour of interfaces with variable dilatancy., Computers and Geotechnics 9 (1990) 47-58.

S. C. D'Aguiar, A. Modaressi-Farahmand-Razavi, J. A. dos Santos, F. LopezCaballero, Elastoplastic constitutive modelling of soil-structure interfaces under monotonic and cyclic loading., Computers and Geotechnics 38 (2011) 430-447. 
C. Cekerevac, S. Girardin, G. Klubertanz, L. Laloui, Calibration of an elastoplastic constitutive model by a constrained optimisation procedure., Computers and Geotechnics 33 (2006) 432-443.

P. Hicher, A. Rahma, Micro-macro correlations for granular media. Application to the modelling of sands., European Journal of Mechanics. A/Solids 13 (6) (1994) 763-781.

F. Lopez-Caballero, A. Modaressi-Farahmand-Razavi, F. Elmi, Identification of an elasto-plastic mode parameters using laboratory and in situ tests., In: In Di Benedetto et al, editor, Deformation Characteristics of Geomaterials IS Lyon, Balkema (2003) 1183-1190.

F. Lopez-Caballero, A. Modaressi-Farahmand-Razavi, H. Modaressi, Nonlinear numerical method for earthquake site response analysis i - elastoplastic cyclic model and parameter identification strategy., Bull Earthquake Eng 5 (2007) 303-323.

P.-Y. Hicher, Multiscale Geomechanics, Wiley, John \& Sons, 2011.

R. C. Gomes, Effect of stress disturbance induced by construction on the seismic response of shallow bored tunnels., Computers and Geotechnics 49 (2013) 338351.

\section{Appendix A. Basic Motion Notions}

For a deformable body considering purely mechanical behaviour let $X$ and $x$ be the reference and the current position vector of a material particle, respectively.

- Deformation gradient tensor

$$
\mathbf{F}=\frac{\partial}{\partial X}(\mathbf{x}), \quad J=\operatorname{det} \mathbf{F}>0
$$

which can be decomposed recalling the polar decomposition theorem

$$
\mathbf{F}=\mathbf{R} \cdot \mathbf{U}=\mathbf{V} \cdot \mathbf{R}
$$


where $\mathbf{U}$ and $\mathbf{V}$ are symmetric, positive definite tensors whose principal values are the stretch ratios of the deformation, right and left respectively, and $\mathbf{R}$ is an orthogonal tensor called the local rotation tensor.

- Particle velocity

$$
\mathbf{v}=\dot{\boldsymbol{x}}=\frac{\partial}{\partial t}(\mathbf{x})
$$

- Velocity gradient tensor

$$
\begin{aligned}
\mathbf{L}=\frac{\partial}{\partial x}(\mathbf{v})=\frac{\partial}{\partial X}(\mathbf{v}) & \cdot \frac{\partial}{\partial x}(\mathbf{X})=\dot{\boldsymbol{F}} \cdot \mathbf{F}^{-1}=-\mathbf{F} \cdot \dot{\boldsymbol{F}}^{-1} \\
\mathbf{L} & =\mathbf{D}+\mathbf{W} \\
\mathbf{D} & =\frac{1}{2}\left(\mathbf{L}+\mathbf{L}^{T}\right) \\
\mathbf{W} & =\frac{1}{2}\left(\mathbf{L}-\mathbf{L}^{T}\right)
\end{aligned}
$$

These variables represent the decomposition of $\mathbf{L}$ where $\mathbf{D}$ is the rate of deformation tensor (symmetric) and $\mathbf{W}$ is the spin or vorticity tensor (skew symmetric). $\mathbf{D}$ and $\mathbf{W}$ can be written in terms of $\mathbf{F}$

$$
\begin{gathered}
\mathrm{D}=\frac{1}{2} \cdot \mathbf{R}\left(\dot{\boldsymbol{U}} \cdot \mathbf{U}^{-1}+\mathbf{U}^{-1} \cdot \dot{\boldsymbol{U}}\right) \cdot \mathbf{R}^{T} \\
\mathbf{W}=\frac{1}{2} \cdot \mathbf{R}\left(\dot{\boldsymbol{U}} \cdot \mathbf{U}^{-1}-\mathbf{U}^{-1} \cdot \dot{\boldsymbol{U}}\right) \cdot \mathbf{R}^{T}+\dot{\boldsymbol{R}} \cdot \mathbf{R}^{T}
\end{gathered}
$$

or, similarly, by considering the left polar decomposition

$$
\begin{aligned}
& \mathbf{D}=\frac{1}{2}\left(\dot{\boldsymbol{V}} \cdot \mathbf{V}^{-1}+\mathbf{V}^{-1} \cdot \dot{\boldsymbol{V}}+\mathbf{V} \cdot \dot{\boldsymbol{R}} \cdot \mathbf{R}^{T} \cdot \mathbf{V}^{-1}-\mathbf{V}^{-1} \dot{\boldsymbol{R}} \cdot \mathbf{R}^{T} \cdot \mathbf{V}\right) \\
& \mathbf{W}=\frac{1}{2}\left(\dot{\boldsymbol{V}} \cdot \mathbf{V}^{-1}-\mathbf{V}^{-1} \cdot \dot{\boldsymbol{V}}+\mathbf{V} \cdot \dot{\boldsymbol{R}} \cdot \mathbf{R}^{T} \cdot \mathbf{V}^{-1}+\mathbf{V}^{-1} \dot{\boldsymbol{R}} \cdot \mathbf{R}^{T} \cdot \mathbf{V}\right)
\end{aligned}
$$


Appendix B. Model Parameters 


\begin{tabular}{|c|c|c|}
\hline \multicolumn{3}{|c|}{ Model parameters } \\
\hline Sand type & Ottawa sand & Illinois River sand \\
\hline \multicolumn{3}{|l|}{ Elasticity } \\
\hline$K_{\text {ref }}(M P a)$ & 296.0 & 296.0 \\
\hline$G_{r e f}(M P a)$ & 222.0 & 222.0 \\
\hline$n_{e}$ & 0.40 & 0.40 \\
\hline$p_{r e f}(M P a)$ & 1.0 & 1.0 \\
\hline \multicolumn{3}{|c|}{ Critical State and Plasticity } \\
\hline$\phi_{p p}^{\prime}\left({ }^{\circ}\right)$ & 33 & 34 \\
\hline$\beta$ & 52 & 45 \\
\hline$d$ & 2.00 & 2.00 \\
\hline$b$ & 0.22 & 0.25 \\
\hline$p_{c o}(M P a)$ & 0.45 & 0.40 \\
\hline \multicolumn{3}{|c|}{ Flow Rule and Isotropic Hardening } \\
\hline$\psi\left(\left(^{\circ}\right)\right.$ & 33 & 34 \\
\hline$\alpha_{\psi}$ & 1.00 & 1.00 \\
\hline$a_{1}$ & 0.0001 & 0.0001 \\
\hline$a_{2}$ & 0.0100 & 0.0150 \\
\hline$c_{1}$ & 0.0600 & 0.0600 \\
\hline$c_{2}$ & 0.0300 & 0.0300 \\
\hline$m$ & 1.00 & 1.00 \\
\hline \multicolumn{3}{|c|}{ Threshold Domains } \\
\hline$r^{e l a}$ & 0.005 & 0.005 \\
\hline$r^{h y s}$ & 0.030 & 0.030 \\
\hline$r^{m o b}$ & 0.800 & 0.800 \\
\hline$r_{i s o}^{e l a}$ & 0.0001 & 0.0001 \\
\hline \multicolumn{3}{|c|}{ Breakage parameters } \\
\hline$a^{b r}$ & 0.01 & 0.006 \\
\hline$m_{a}^{b r}$ & 0.89 & 0.88 \\
\hline$b_{W_{p}}^{a}(M P a)$ & 80 & 120 \\
\hline
\end{tabular}

Table B.2: ECP model's parameters for Ottawa and Illinois River sand 


\section{Appendix C. Illinois River sand results}
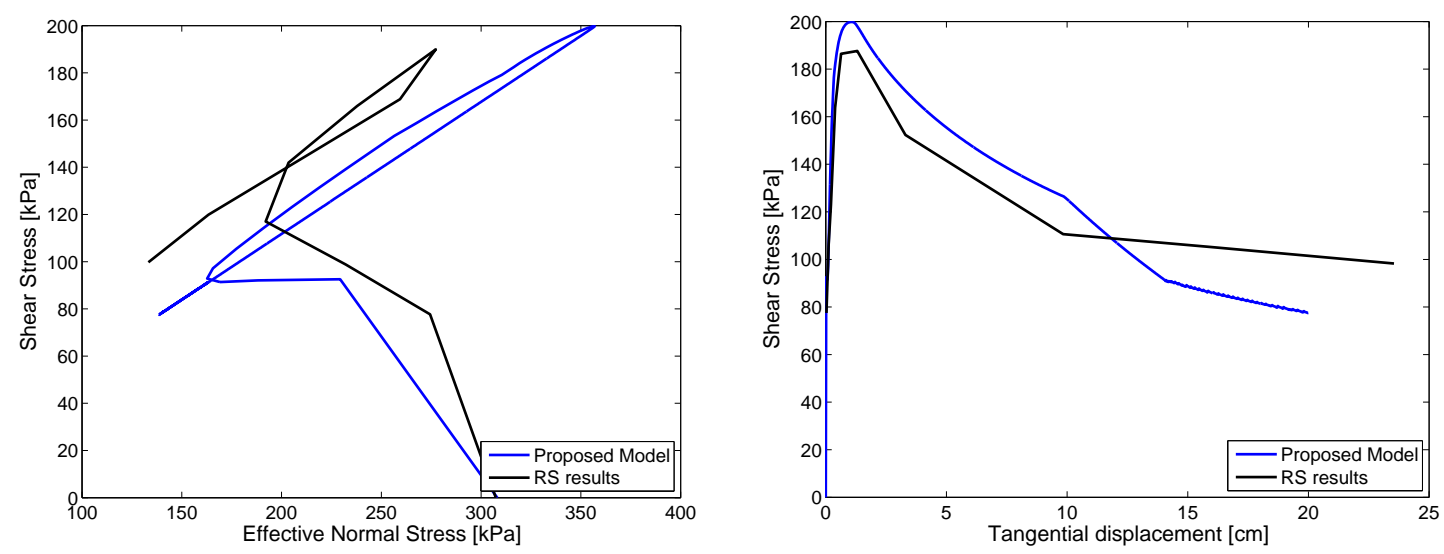

Figure C.21: Illinois River sand : $\sigma_{n}^{\prime}-\tau$ and $u_{T}-\tau$ 

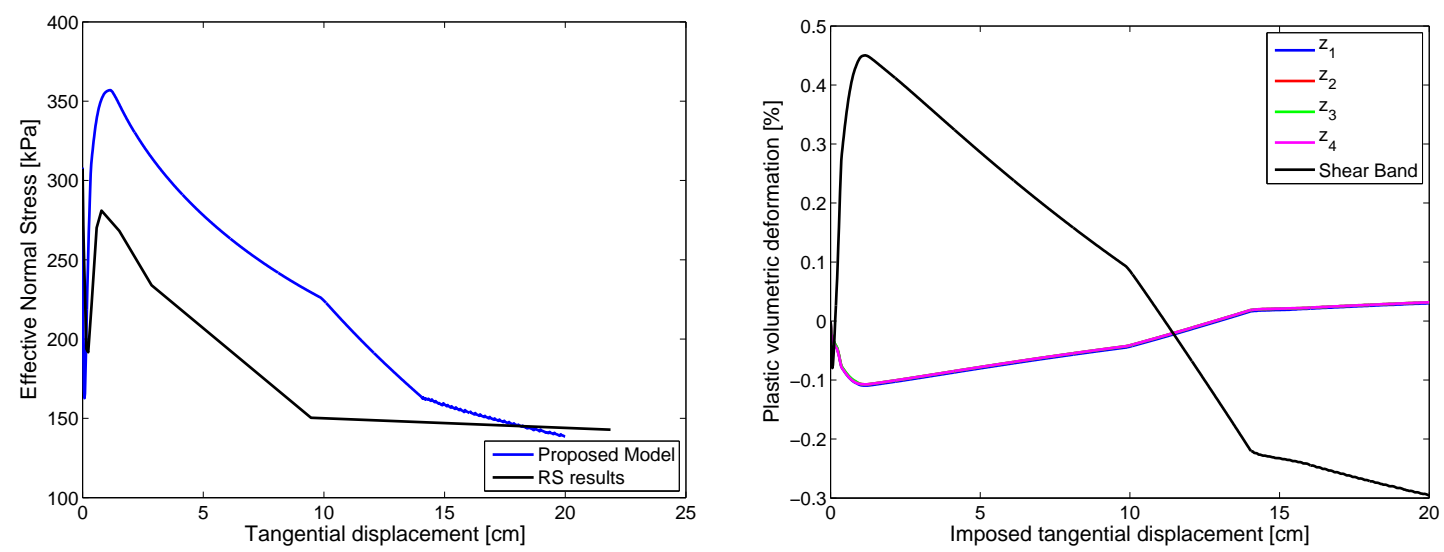

Figure C.22: Illinois River sand : $u_{T}-\sigma_{n}^{\prime}$ and $u_{T}-j^{p}$ 